\title{
Accessibility of urban green infrastructure in Addis-Ababa city, Ethiopia: current status and future challenge
}

Sileshi Azagew ${ }^{1,2^{*}}$ and Hailu Worku²

\begin{abstract}
Many studies have been conducted on the challenges underpinning the depletion and inaccessibility of urban green infrastructures (UGI) in cities of developed countries. Contrary to this, similar studies in rapidly urbanizing cities of Africa are scant. In this study, we assessed the status, accessibility and constraints of UGI in rapidly urbanizing city Addis Ababa, Ethiopia. We first mapped and calculated the status of UGI from 2003 to 2016 based on the land use data in Arch GIS. We then analyzed UGI access such as recreational parks based on proximate and per capita green indicators by using the land use maps, road network and gridded population data. Finally, we examined the challenges behind the current states of UGI based on document review, expert interview and field observation. Our study disclosed that the land use of UGI from 2003 to 2016 is decreased by 9.2\%. The land use of urban agriculture decreased significantly (by 11.9\%) followed by urban forest (by 3.7\%). The accessibility indicators also revealed that the city residents have no sufficient recreational UGI. The city's park per capita was very small $\left(0.37 \mathrm{~m}^{2}\right)$ compared to Ethiopian UGI standards $\left(15 \mathrm{~m}^{2}\right.$ ) and the large portion of the city's population (above $90 \%$ ) has no access to existing parks within the minimum walking distance thresholds. Expansion of built up environment, density, weak implementation of policies and plans, and lack of priority for UGI development were identified as the major constraints behind the current state of UGI in the city. We conclude that UGI is degrading and insufficiently accessible for the city residents due to weak enforcement of development plans, density, built up area expansion, and lack of priority for UGl. Thus, strict adherence to the development plans and regulations is of paramount importance to maintain UGI in the city. Moreover, developing small to median size parks in already proposed areas, new expansion and renewal parts of the city is vital to enhance recreational park access. We hope that this study serves as a benchmark for policy and planning to ensure accessible and adequate UGI in rapidly urbanizing city Addis Ababa and beyond.
\end{abstract}

Keywords: Addis ababa, Park accessibility, Park per capita, Park proximity, Urban green infrastructure, Urban parks

\section{Background}

The world is becoming increasingly urban, and the number of population living in cities is also growing rapidly. United Nations, Department of Economic and Social Affairs (UNESA) forecasted that in 2030 more than $60 \%$ of the world's population would be living in cities (UNESA 2014). Currently, cities occupy only $2.7 \%$ of

\footnotetext{
*Correspondence: sileshi2001@gmail.com

1 Department of Civil Engineering, Haramaya Institute of Technology

(HiT), Haramaya University, P.O. Box-138, Dire Dawa, Ethiopia

Full list of author information is available at the end of the article
}

the Earth's surface (UNESA 2014), but are responsible for $75 \%$ of total energy consumption, $80 \%$ of greenhouse gas emissions and have generically had a harmful effect on natural resources (Gret-Regamey et al. 2013). In order to combat these urbanization imposed challenges urban green infrastructures are becoming a popular strategy in different parts of the world.

Urban Green infrastructure (UGI) is a broad term, and defined as the combined structure and connectivity of recreational parks and other types of green spaces that deliver multiple benefits for urban environment (Jennings et al. 2016; Wolch et al. 2014). The benefit of 
UGI has been widely cited in the literature. In general, it has social (Kaczynski and Henderson 2008), economic (Anguluri and Narayanan 2017), ecological (Mohamed and Zhirayr 2013), as well as planning benefits (Attwell 2000; Baycan-Levent and Nijkamp 2009). From the social point of view, it improves social cohesion and interaction (Tabassum and Sharmin 2013); provide places for physical activity; contribute to the social well-being and the health of the community (Kaczynski and Henderson 2008). Thus, at present days, UGI is embraced by many cities of developed nations to have the aforementioned benefits and create a sustainable urban environment (Foster et al 2011).

Despite the numerous benefits that UGI offers to cities, studies show that these spaces are on the decline in several cities of the world. For instance, a study on changes in land-use of 25 European cities found that, 7.3 to 41 percent of green spaces changed to different land-uses (EEA 2002). Similarly, in the USA, a study on land-use change in 274 metropolitan areas revealed about 1.4 million hectares of green spaces converted to different land use (McDonald et al. 2010). In developing countries the depletion of UGI is more serious than developed nations. Adjei 2014 indicated that in sub-Saharan African countries, components of UGI are depleting at an alarming rate in several cities across the continent. Statistics also showed that green spaces occupied small fraction of the land mass of several urban centers of African countries (Adjei 2014). Moreover, these spaces, especially recreational parks are not accessible to the majority of the urban communities. For instance, recreational parks in Alexandria (Egypt), Luanda (Angola) and Cairo (Egypt) cities were below $1 \mathrm{~m}^{2}$ per city dweller (Langer and McNamara 2011). Studies also indicated that the distribution of urban parks (UPs) should be in a form that is accessible to all the urban communities within a minimum walking distance (Jensen and Koch 2004; Nielsen and Hansen 2007). However, in cities of African countries most urban community has no easily access to recreational parks within the minimum walking distance thresholds. Moreover, there is a lack of empirical studies about the status and accessibility of UGI in cities of African countries.

A considerable amount of literature has been investigated the constraints that contributed to the depletion and inaccessibility of UGI in the cities. For instance, rapid urbanization has been reported as a major cause of green spaces degradation in 274 metropolitan areas of USA (McDonald et al. 2010; Liu et al. 2014) and in Kumasi city, Ghana (Adjei 2014). Studies also indicated that a lack of political desire to enforce regulations (Lara-Valencia and García-Pérez 2015); population densities, poor administration of planning processes at the local level; and a reluctance to make good planning decisions (Pincetl and Gearin 2005) can all affect access to UGI in general and recreational parks in particular.

Despite the fact that the majority of the world's urban population is found within developing countries, very little research has been conducted regarding the constraints that determine UGI provision in rapidly urbanizing cities of developing countries. Rather, earlier studies have focused on developed countries (Giles-Corti et al. 2005; Kabisch, and Haase 2013; Baycan-Levent and Nijkamp 2009). In other word, the rapidly urbanizing countries of African differ substantially from developed nations in social, economic, cultural and political aspects. As a result, recommendations for cities in developed countries may not necessarily be valid for such rapidly urbanizing cities. Thus, more additional studies are needed in terms of African context and it is the target of the current study to fill this knowledge gap by taking the capital city of Ethiopia, Addis Ababa as a case.

Addis Ababa city is experiencing a rapid population growth. With this rapid population growth, there is an increase in density of built spaces, expansion of housing, infrastructure development, and restructuring of industrial areas in the peripheral part of the city (Abeje 2007; Fetene and Worku 2013). It is also indicated that, the urban forest and other green components of Addis Ababa city are distracting (Fetene and Worku 2013). Even though, the city proposed different components of UGI during the last two structural plan revision periods (in 2003 and 2016), the existing situation of the city shows that there is no sufficient amount of accessible UGI for the city residents (Abeje 2007). As aforementioned, there are a number of factors that may contribute to the depletion and the insufficient accessibility of UGI in the city. The expansion and density of the built environment are the major factor that may affect UGI (Pincetl and Gearin 2005). In addition to this, it is important to intensively explore all other possible challenges of UGI in order to evolve plausible policy direction and strategies that helps to improve and maintain UGI. Moreover, there is limited data on the current status and accessibility of UGI in the city, and the available information is scant, fragmented and needs to be improved.

A variety of approaches have been used in the literature to quantify and assess the status and accessibility of UGI. The size of UGI includes acreage or percentage of UGI within a certain boundary, which can be analyzed by using Geographic Information Systems (GIS) is one indicator (Taylor et al. 2011; Kabisch and Haase 2013; Yao et al. 2014). The other indicators used to assess the spatial accessibility of UGI such as recreational parks are per capita green index and proximity indicator. In this study recreational parks are defined as components 
of UGI that provide recreational service for the city residents. Throughout this article we used urban parks (UPs) to represent recreational UGI. Per capita green index is the most widely used indicator to assess green space access and described as the total area of UPs averaged by the total population within the geographic area (Taylor et al. 2011; Kabisch and Haase 2013). This indicator vary globally and among cities. For instance, World Health Organization (WHO) suggested $9 \mathrm{~m}^{2}$ park per capita for the world and $7 \mathrm{~m}^{2}$ for cities of African countries (WHO 2016). Most developed countries adopt a $20 \mathrm{~m}^{2}$ park area per capita (Wang 2009), and Urban Green Infrastructure Standard (UGIS) of Ethiopia also suggested $15 \mathrm{~m}^{2}$ park per capita (MoUD 2015). Though the per capita ratio standard is widely accepted owing to simplicity in application, it is not considered effective as it does not consider the spatial distribution or accessibility of green spaces to users (Yao et al. 2014; de la Barrera et al. 2016). Thus, for an integrated assessment of cities UGI access, in addition to per capita green index, "accessibility/proximity indicator is suggested to be studied together (Yao et al. 2014; de la Barrera et al. 2016). Proximity indicator is often denoted in terms of the level of services area of UPs at a given distance and the number of the population within the service area (Wright et al. 2011). In this study, these two indicators were also used to carry out the comparison of available UPs with the benchmarks provided by Ethiopian UGIS and WHO standard so as to indicate the service area gap or deficit of UPs at city and sub-city scale.

Therefore, the overall objective of this study is to examine the status, accessibility and challenges of urban green infrastructure in Addis Ababa city. To this end, the current study has aimed at answering the following four questions; what is the status and trend of urban green infrastructure in the city? How much the available UGI such as recreational parks are accessible for the city residents and what amount of recreational parks is needed to fulfill the current demand? What are the challenges and constraints behind the current states of urban green infrastructure in the city? What are the policy and planning implications?

\section{Methods and materials}

\section{Description of the study area}

This study was conducted in Addis Ababa, which is the capital city of Ethiopia. Addis Ababa is a chartered city having three layers of government: one municipality, ten sub-cities and 116 districts/Woredas (Fig. 1). The total area of the city is $526.99 \mathrm{~km}$ square. The city serves as a social, economic and political center for the country. Its total population as of August 2019 estimated to be 4,592,000 with an annual growth rate of 4.4 percent
(CSA 2019). This constitutes approximately 20 percent of Ethiopia's urban population. The population growth in the city is far out pacing economic growth, resulting in a large slum and squatter settlements. Until recently, slum houses occupied more than $75 \%$ of the city (CSA 2017).

Addis Ababa city is endowed with different components of UGI. In the city's context, UGI is classified into four major categories including urban forest, river and riverside green, urban agriculture and recreational parks. However, the increasing density of built spaces in the inner part, the expansion of housing construction and restructuring of industrial areas in the peripheral part of the city is affecting these green components of the city (Climate change and Urban Vulnerability in Africa 2013). Hence, more detail investigation is needed to know their current status, accessibility and constraints.

\section{Assessment of the status of green infrastructure}

In order to assess the status of UGI in Addis Ababa city our study examined the land use condition of UGI for the last 13 years from 2003 to 2016. The years were selected because they coincide with the revision period of structural plan of the city. The commonly used technique for assessing the status of green space is the Normalized Difference Vegetation Index (NDVI) using satellite imagery data (Lahotia et al. 2019). However, such methodology fails to consider different components of green spaces available in the city (Anguluri and Narayanan 2017; Lahotia et al. 2019). Hence, this research used the land use map that was extracted from the structural plan of the city for quantifying different components of UGI in Arc GIS tool. Moreover, the structural plans data is more reliable and accurate than satellite images because it was collected directly through a field survey by using GPS and other tools. The structural plan shape file data of the year 2003 and 2016 was collected from Addis Ababa City Integrated Development Plan Project Office (AAIDPO).

Furthermore, the city administration did not update the spatial data of existing UPs. Thus, a field survey was also conducted to identify the location of existing UPs by using GPS. After the field survey was undertaken, the collected GPS point data of UPs were imported into the GIS environment and overlaid on the existing land use plan of the city. Then, with same geographical projection and coordinate system, the accurate location of existing UPs was identified and the polygon of each UPs was extracted from the land use map. The details of Geo-referencing, mapping and accuracy assessment are further elaborated in detail in the previous work (Lahotia et al. 2019).

There is no universally accepted land use land cover classification since it is influenced by the specific users' objective and the geographical location of the land (Thompson 1996). Thus, for the purpose of this study, 

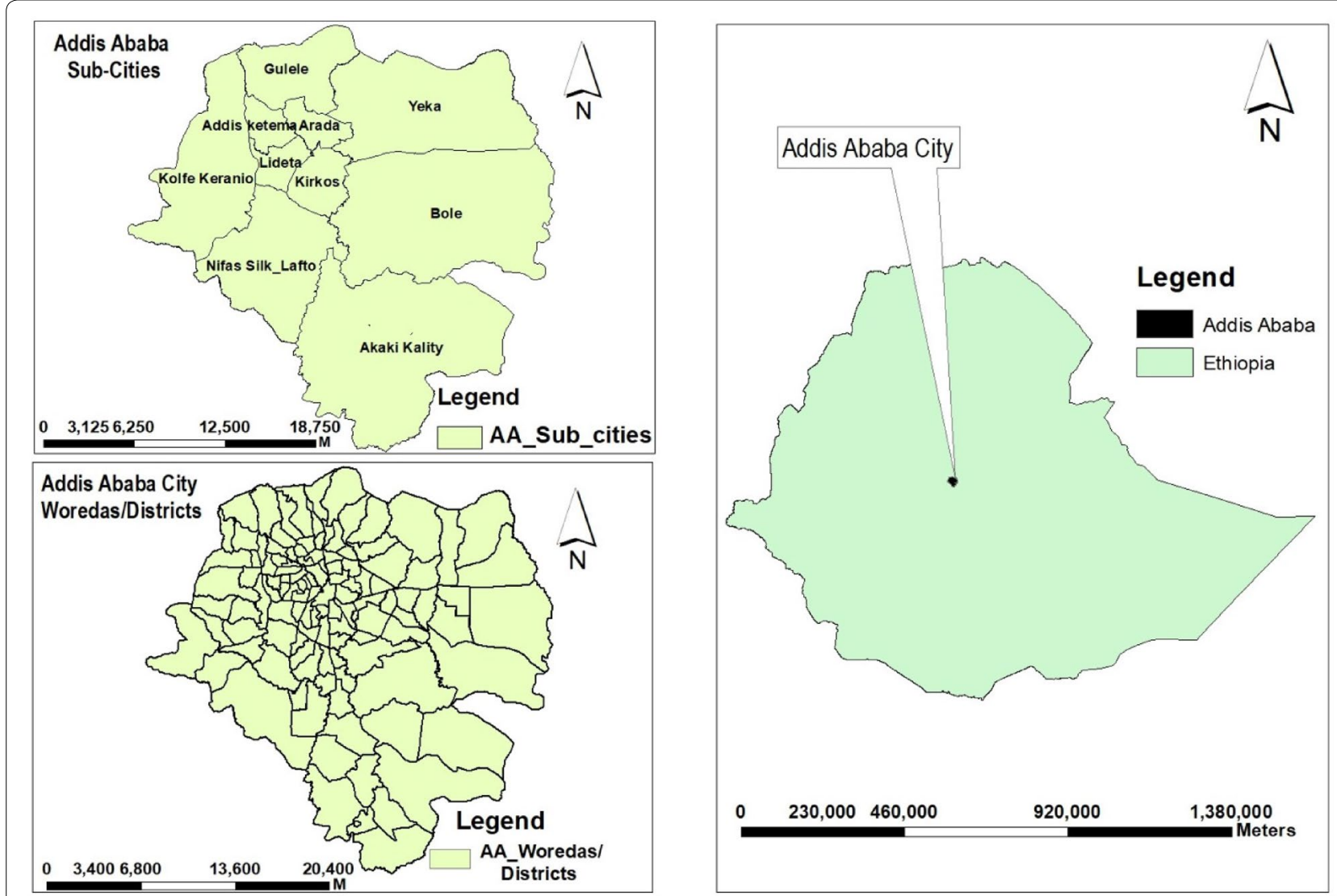

Fig. 1 Map of Addis Ababa city

we have chosen five land use class and extract from the structural plans of the city (Table 1). The land uses include the four UGI components (Urban forest, urban agriculture, river and riverside green, and UPs) and built up area. We merged all built up land uses (residential, commercial, industrial area, transportation network and other built infrastructure) into one land use category to understand how much it affects UGI (Table 1).

There are different indicators that are used to assess the states of UGI. The size of UGI in terms of acreage or percentage is one indicator which is widely used (Kabisch and Haase 2013; Yao et al. 2014). GIS has provided a convenient technique to analyze the status and changes in the components of UGI based on the mentioned indicator. Thus, the land use of each UGI component and built up area for the year 2003 and 2016 was calculated in Arch GIS in terms of acreage or percentage. And then, the variation in each land use between the year 2003 and 2016 was analyzed. The percentage of change or variation in land use of each UGI component (urban forest area, urban agriculture, riverside green and UPs), and built up area of the city was calculated based on the equation described below i.e. Equation 1-2 (Kabischa and Haasea 2012):

$$
\operatorname{LULCj}=\frac{\operatorname{LULC}(\mathrm{t} j+1)-\operatorname{LULC}(\mathrm{t} j)}{\mathrm{tj}+1-\mathrm{tj}}
$$

where:LULC $j$ are all land use land cover in the year $t j$ with $\mathrm{j}=1 \ldots 3$ and

$$
\mathrm{t} 1=2003 \text {, and } \mathrm{t} 2=2016
$$

$$
\triangle \operatorname{PLULCj}(\%)=\operatorname{LULCj} \frac{1}{\mathrm{LULCtj}} \times 100
$$

where: $\triangle \mathrm{PLULCj}(\%)$ is percentage of land use land cover change.

\section{Assessing the spatial accessibility of Urban Green Infrastructure}

In this study the spatial accessibility analysis of UGI followed the definition by Coles and Grayson (2004), which define urban green space based on their access and function criteria. Thus, in this analysis only UGI covered by vegetation and used for recreational purpose that serve 
different needs of the urban community are considered. UGI type that serves for recreational purpose in Addis Ababa city is UPs. Hence, the main focus of this analysis was on UPs that provide recreational service for the city residents. Although, urban forest, agricultural land and river and riverside green are equally important, they are not considered because they do not qualify the recreational function of UGI, and their current states are unsuitable for recreational service. As indicated by Addis Ababa City Beautification, Parks and Cemetery Development and Administration Agency (AABPCDAA) the available UPs in the city is very small. Thus, the spatial accessibility analysis was conducted for all identified available UPs in all sub cities (10 sub-cities) of Addis Ababa city.

The spatial accessibility analysis of UPs requires a Geospatial database used in ArcGIS. Types of data used to develop the database include, administrative boundary shape file, the layer of the existing UPs and land use of the city. The road network shape file and population density data of the city and each sub-city were also used for the analysis (Fig. 2b). All these data were collected from Addis Ababa city administration and existing UPs data were collected through field survey. The last census in Ethiopia was conducted in 2007 and this study used the 2019 project population data by CSA of Ethiopia (Fig. 2a).

As indicated by La Rosa (2014), accessibility is a broad term and is often "misused" and confused with terms like "mobility". Academicians and urban researchers also widely recognized accessibility as a complex multidimensional construct that is associated with both spatio-physical and socio-personal factors. In our study, UPs access is objectively measured UPs accessibility (spatial accessibility) based on quantitative standards, i.e. proximity indicator and park area per capita (Lahotia et al. 2019; Barbosa et al. 2007). The detail methodology for analyzing data in each indicator explained below.

\section{Per capita green indicator}

For calculating the park per capita, the aggregate of UPs acreage available for the city and each sub-city is calculated using "calculate geometry" tool in ArcGIS 10. Then per capita park index was calculated based on city and each sub-city population. Equation 3 was used for calculating per capita green index (Anguluri and Narayanan 2017).

$$
A P i=\sum_{i=0}^{n} \frac{G A i}{S P i}
$$

where; GAi-refer to the park area and SPi-is a population which enjoys services within the boundaries of the sub-city i, APi- per-capita park index indicated the amount of parks available in a sub-city for every inhabitant of the sub-city.

Whereas, to calculate the service area gap/deficit of UPs in the city Eq. 4 was used (Anguluri and Narayanan 2017).

$$
G A g=(N p-A p i) \times P
$$

where; GAg-shows a shortage area of the park, P- Population number of the region, NP-denotes the international standard and APi-per-capita park index indicated the amount of parks available in a sub-city for every inhabitant of the sub-city.

\section{Proximity indicator}

in addition to the per capita green indicator, this study used proximity indicator to examine level of UPs access to the city population. It is the widely used indicator to assess the proportion of the population having access and without access to UPs that was modelled in GIS using Euclidean or network distance (Nicholls 2001).

As a minimum standard, planners have been able to establish some general principles about the willingness and ability of residents to walk to their nearest

\begin{tabular}{|c|c|}
\hline LULC classes & Description of each LULC class \\
\hline Built-up area & $\begin{array}{l}\text { Include areas with all types of artificial surfaces, including residential, commercial, industrial area, transportation network and } \\
\text { other built infrastructure }\end{array}$ \\
\hline Urban agriculture & This includes cultivated lands, community lands along the river banks that are used for agricultural purpose \\
\hline Urban forest & $\begin{array}{l}\text { Include areas of dense vegetation cover, such as areas covered with both indigenous and exotic trees like Eucalyptus tree, } \\
\text { grass and shrub areas }\end{array}$ \\
\hline River and riverside green & It includes rivers, streams, riverside or buffer greens and other water bodies \\
\hline Urban parks & $\begin{array}{l}\text { Urban parks refers to a specific piece of ground, excluding natural parks, within the city/town and set apart for recreational } \\
\text { use by the public. It may be planted with trees, lawns and other shrubbery and include facilities for sport, entertainment, } \\
\text { and recreation purpose }\end{array}$ \\
\hline
\end{tabular}

Table 1 Land use land cover class (LULC) 

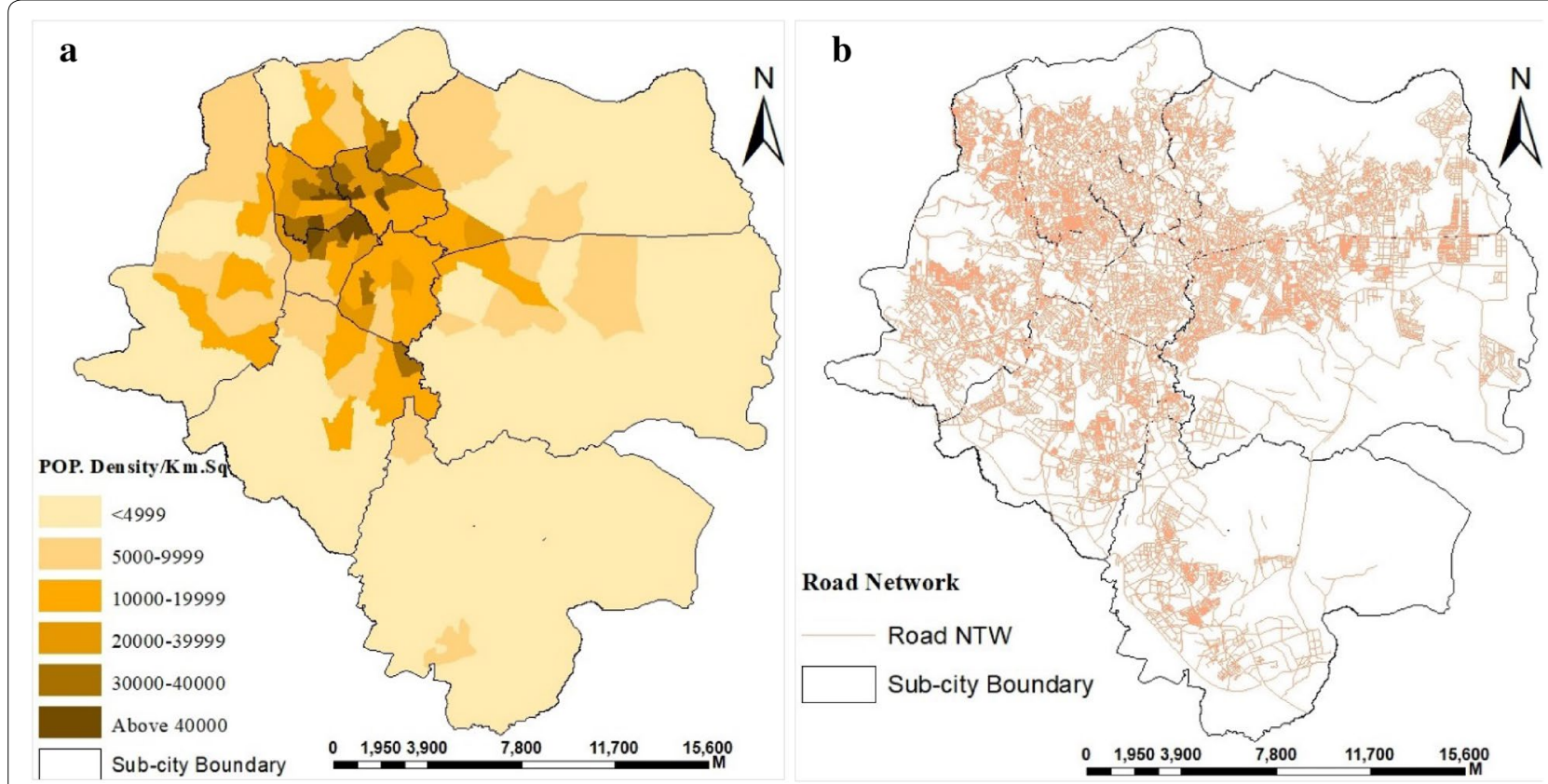

Fig. 2 a Population density map, and $\mathbf{b}$ Road network map of Addis Ababa city

neighborhood park (Nicholls 2001; Van Herzele and Wiedemann 2003; Boone et al. 2009). Even though there is a lack of such standards for measuring the accessibility of UPs in Ethiopian context, it is necessary to establish some standards against which the citywide park access can be evaluated. Several walking distance standards were employed in literature to calculate the effective service areas of UPs, such as 250, 300, 400, 800 and $1000 \mathrm{~m}$ (Nicholls 2001; Tan and Samsudin 2017). Since this study has focused on daily services of UPs within walking distance, two distances were applied, a $400 \mathrm{~m}$ (5 min walking distance) and $800 \mathrm{~m}$ (10 min walking distance). The former is a comfortable distance while the latter is a little bit long, but still acceptable for most adult people.

Different proximity measurement techniques are used for determining neighborhoods with good park accessibility (Nicholls 2001; La Rosa 2014). In this study GIS based Network distance rather than Euclidian distance was used to calculate the service area of UPs, since it has been shown that the former is more accurate (Nicholls 2001; La Rosa 2014). Many studies also choose GIS based network analysis method because it has an advantage over Euclidian distance as it reflects the actual travel and consider all the barriers that make routes inaccessible by park users (La Rosa 2014). For comparison and visualizing the difference the study produced the maps of park service area by using both techniques (Figs. 5 and 6).

The accessibility or proximity analysis begins with an evaluation of the general park service coverage on a citywide and sub-city level using GIS. Then, the study estimated the population with potential urban park access at the city and sub-city levels. As mentioned above, ArcGIS based Network Analyst 's Service Area Analysis tool was used to create a $400 \mathrm{~m}$ and $800 \mathrm{~m}$ walking distance service area (polygon) that defines the spatial extent of each park access. An additional setting under the "multiple facilities option" was also used to make each polygon discrete, not allowing the polygons to coincide. These separate, non-overlapping polygons are used to represent the service area for each park. Then the created service areas of parks and point data of the city population were overlaid on top of each other to calculate park service area, and total number of population lying inside and outside each service area. Thus, individuals located within a service area were assumed to have better access and easily use that particular park daily than people a bit farther away from a park (Sister et al. 2007). A high service population ratio means that inhabitants of residential areas could benefit more, and a high service area ratio means greater accessibility of UPs for inhabitants in residential areas.

The accessibility was calculated based on the following equations: first the ratio of the service area of UPs within 400 and $800 \mathrm{~m}$ walking distance was determined by Eq. 5 . As this ratio applied the population of neighborhood parks, the 'total impact area population' was calculated by Eq. 6 , 


$$
S A R=\frac{P S A}{T A-P A} \times 100 \%
$$

where; SAR is a service area ratio, PSA is a service area of parks, TA is the total area of the city and PA is parks area.

$$
A I=\frac{N A}{N T} \times 100 \%
$$

where; $\mathrm{AI}$ is accessibility indicator, which measures the proportion of the urban population that lives within the service area of UPs. NA is the number of urban inhabitants who live within the $400 \mathrm{~m}$ or $800 \mathrm{~m}$ walking distance to an urban park. NT is the total number of urban inhabitants within the city.

\section{Examining challenges and constraints of urban green infrastructure}

The challenges and constraints of UGI are initially derived from the result of the study and then, supported by the analyses of secondary materials, personal observations, and interviews with a variety of government organizations that are responsible for UGI management. Personal observation was made by the researchers in order to see the current states of UGI, and to crosscheck the proposal in the structural plan and the implementation on the ground. Interviews with purposefully selected government officials and experts were also conducted. Ten key informants were selected from four governmental institutions of the city such as Addis Ababa City Environmental Protection Agency (AAEPA), Addis Ababa City Beautification, Parks and Cemetery Development and Administration Agency (AABPCDAA), Addis Ababa City Urban Planning Institute and Addis Ababa City Urban Agriculture Bureau. These government institutions were selected because they are responsible for planning and managing components of UGI. For instance, AAEPA is responsible for riverside green and urban forest development, AABPCDAA mange UPs and other recreational areas, Urban Planning Institute is responsible for planning and land use development of the city and etc. The ten informants were also selected from these institutions based on their educational background and expertise about UGI practice in the city.

The interviews were open ended and conducted on a face to face basis and through phone calls. A total of 10 interviews was conducted with each interviewee. The interview questions were prepared and conducted in Amharic language and then translated to English language. The interviews lasted between $30 \mathrm{~min}$ to 1 and half hour. The main points of the interviews were about current condition of UGI, availability of UGI regulations, laws or rules and their level of enforcement, management of UGI and related constraints. These interviews were conducted to gain in-depth information from the experts who have knowledge about UGI practice in the city.

\section{Result}

\section{Status of urban green infrastructure in Addis Ababa}

As indicated in methodology part, UGI in Addis Ababa city context is classified into four major categories including urban forest, river and riverside green, urban agriculture and UPs. To have a general understanding about the status of these components, this study evaluated land use change of components of UGI from 2003 to 2016 (Fig. 3 and Table 2). Accordingly, in 2003, the land use of UGI covered 20956 ha (40.3\%) of the city area. This has, however reduced to 16,262.8 ha in 2016 representing $31.1 \%$ of the total land uses of the city. When we look at the land use share of each component of UGI, in 2003 urban forest (23.4\%) has the highest coverage followed by urban agriculture (13.8\%). However, UPs that serve for recreational function have the least coverage than other components of UGI. Again in 2016, the land use of urban forest had the highest coverage followed by river buffer land use. Even though good emphasis was given for UPs during the 2016 structural plan, still the land use of UPs in relation to other components of UGI was very small (1.8\%).

When we look at the land use of urban forest, it was 12168 ha which covers $23.4 \%$ of the city area in the year 2003 (Table 2). It has, however, decreased to $10,301.5$ ha in the year 2016 and this covers $19.7 \%$ of the city area. This coverage includes the forest covered, forest uncovered and proposed regional forest. Currently, urban forest covered area in Addis Ababa is mostly found in the north and northeast part of the city. Some forest patches are also found in the northwest and southwest part of the city. However, other forest land of the city converted to built-up area and other land uses. For instance, the reserved land for woodland forest in Akaki Kality and forest patches in Nifasilik sub cities were converted to built-up area (Fig. 3).

The situation of urban agriculture in the city is quite alarming. In 2003 agricultural land use of the city covered 7176 ha and this represents $13.8 \%$ of the city area (Table 2). The major agriculture sites during this period were Koye, Wedesso, Idoro, Fetche, Akaki, Beseka, Abebora, Dongora, Harbu, Jemo, Bulbula, Bole weregenu, Dire-migra, mekanissa and Lafto. However, the amount of agricultural land use was very much decreased (938.7 ha) in the year 2016 (Table 2). Most of the aforementioned agricultural sites were converted to other land uses such as condominium and real estate housing sites and industrial development area. 
Regarding river and riverside green, the city has 7 major and 6 medium rivers which are fed by 75 small streams (Fig. 4). These rivers and streams are mostly seasonal and start from the north, northwest and northeast and flow towards the southern part of the city and ended at Lake Aba Samuel. The major rivers of the city are Kebena, Ketchene, Little Akake, Kurtame, Bantiyketu, West Akaki and East Akaki (Fig. 4). In 2003, the land use of river and riverside green was about 1144 ha $(2.2 \%$ of the city area) and this was increased to 4026.5 ha (7.7\%) in 2016 (Table 2). However, based on field observation and interview with experts, the proposed riverside green development during 2003 was not implemented. Most of the proposed riverside buffer strips are highly abused and occupied by squatters and informal settlers.

Moreover, we observed that rivers and streams are increasingly choking with uncollected garbage and solid waste from households, and industrial waste in the form of liquid effluence, agro-chemicals, petrochemicals and metals.

In addition, in 2003 the city had 468 ha of UPs land use. From this 188.8 ha was existing UPs and 279.2 ha was proposed UPs (Table 2). However, almost all proposed UPs during 2003 was not realized and implemented. During this period, the city had very few existing UPs and three sub-cities including Akaki Kality, Lideta and Addis Ketema had no any existing UPs at all. In 2016 the city again allocated 825 ha of additional land for UPs development (Table 3). Nefas Silk, Gullele and Kolfe Keraniyo sub-cities have allocated the highest number of plots of land for UPs respectively, and Bole sub-city allocated small number of plots of land for UPs. Until this research is undertaken, the city has 29 existing UPs with a total area of 168.7 ha (Table 3). Despite the recent development of the number of additional UPs, the total area of existing UPs is decreased by 20.1 ha compared to the total area of existing UPs in 2003. Out of ten sub-cities, Addis ketema has no existing UPs and Lideta sub-city has better number of UPs than other sub-cities (Fig. 4).

In general, when we look at the change in land use of UGI from 2003 to 2016, about 4693.2 ha (9.2\%) of UGI had been decreased or converted to other land uses. On the other hand, the proportion of built-up area has increased by the same figure. The land use of urban agriculture was very much decreased (by 11.9\%) followed by urban forest which was decreased by $3.7 \%$ (Table 2 ). Many of the converted urban forest land use were undeveloped or proposed lands. However, the land use of UPs and river buffer green were increased by $0.9 \%$ and $5.5 \%$ respectively. This is because the city allocated more additional lands for UPs and river buffer green during the revision of 2016 structural plan of the city (Table 2). Figure 4 also clearly indicates the variation in land use of UGI components between the year 2003 and 2016.

\section{Accessibility of existing urban parks Per capita of existing urban parks}

When the per-capita of currently existing UPs is evaluated, the overall city average is $0.37 \mathrm{~m}^{2}$ and it ranges from 0 to $0.86 \mathrm{~m}^{2}$ at sub-city level. Among the sub-cities, Arada and Kirikos have relatively the highest ratio, while the other sub-cities have the lowest park per person ratio. The densest sub-cities such as Lideta $\left(36,840\right.$ per $\left.\mathrm{km}^{2}\right)$ and Addis ketema $\left(49,550\right.$ per $\left.\mathrm{km}^{2}\right)$ have a very small park per-capita in relation to other sub-cities (Table 4). The percentage of UPs to the total area of the city was $0.32 \%$ and ranges from 3.2 to $0.05 \%$ in sub-cities (Table 4 ).

\section{Proximity of existing urban parks}

As indicated in Sect. 2.3, based on road network and simple buffer technique in ArcGIS, the service area map of UPs was produced for visualizing the difference between the two techniques (Figs. 5 and 6). However, all the accessibility analysis was made by road network analysis technique. Table 5 shows the total park service area and the number of city residences that can access parks within the service area. The results showed that the service area within $400 \mathrm{~m}$ covered $3,234,458 \mathrm{~m}^{2}(0.6 \%)$, while the service area within $800 \mathrm{~m}$ covers 15,881,803 $\mathrm{m}^{2}$ (3.0\%) of the residential area of Addis Ababa city. In addition, more than 126,383 and 520,957 population of the city resident are live within $3,234,458 \mathrm{~m}^{2}$ and $15,881,803 \mathrm{~m}^{2}$ service area of UPs respectively. This mean $2.8 \%$ of the city dwellers has access to UPs within $400 \mathrm{~m}$ walking distance, and $11.3 \%$ of the city dwellers can access UPs within $800 \mathrm{~m}$ walking distance. This indicated the mismatch in available urban park service area with the city population and the improper spatial distribution of existing parks with respect to built-up land use.

When the percentage of park service coverage for each sub-city is evaluated, only 3 sub-cities (Lideta, Kirkos, and Arada), which represent $6.4 \%$ of the city area have more than $3 \%$ of their area fall within the $400 \mathrm{~m}$ distance and more than $16 \%$ of their area fall within $800 \mathrm{~m}$ walking distance. Lideta has relatively the highest park service area in both distance thresholds followed by Arada sub-city (Table 5). The three outlying large sub-cities such as Bole, Akaki Kality, and Nefas Silk Lafto have the lowest park service area and the highest demand of UPs respectively. 


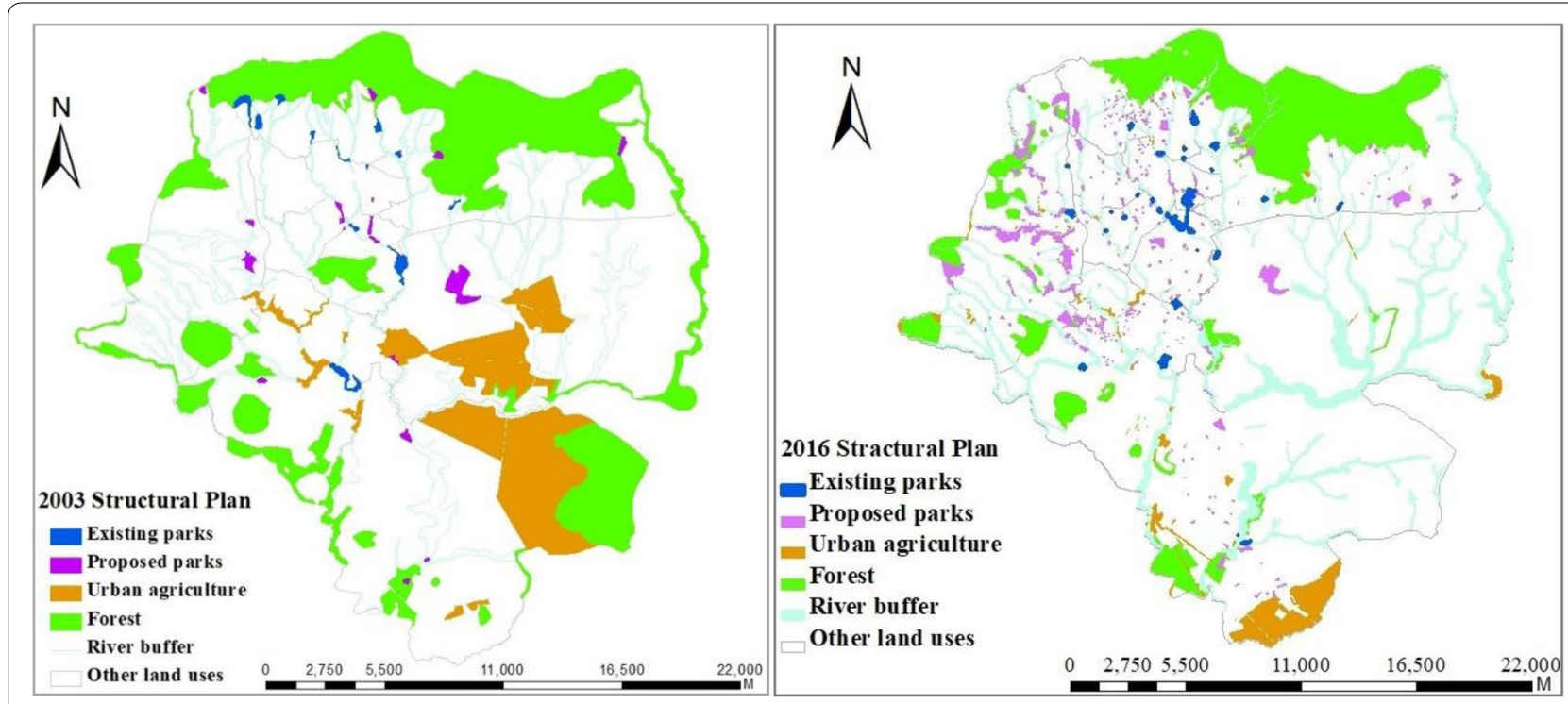

Fig. 3 Land uses maps of UGl of Addis Ababa city in the year 2003 and 2016. Source: Produced by the authors from 2003 and 2016 structural plan and field survey

When the number of each sub-city population within park service areas is analyzed, Lideta (20.4\%) and Kirkos (4.6\%) have relatively the highest served population, whereas the three big sub-cities Akaki Kality (0.4\%), Nifas Silek (0.4\%), Addis Ketema (0.4\%) and Bole $(0.2 \%)$ have the lowest number of served population within the $400 \mathrm{~m}$ distance. Again, Lideta (66.5\%), Kirikos (19.3\%) and Arada (15.9\%) sub-cities have relatively the highest number of population that have access to UPs within $800 \mathrm{~m}$ walking distance. Other sub-cities have the small number of population that fall within the service area of $800 \mathrm{~m}$ walking distance. Overall, the proximity of UPs to the city residents within the walking distances of $400 \mathrm{~m}$ and $800 \mathrm{~m}$ is inadequate and the majority of the city residents are forced to walk more distances to use UPs.

The study also evaluated the level of park pressure in each sub-cities based on mean park service area per served population to know the congestion level at each sub-city. Considerable differences in park pressure was found within a $400 \mathrm{~m}$ walking distance, ranging from $186.3 \mathrm{~m}^{2}$ per person in Akaki Kality and $12.3 \mathrm{~m}^{2}$ per person in Lideta, which is the highest park congestion. In general, Lideta, Arada and Addis Ketma have more park pressure than other sub-cities.

\section{Level of deficit in park service area}

The current UPs per capita $\left(0.37 \mathrm{~m}^{2}\right)$ of the city and each sub-cities of Addis Ababa were computed with the Ethiopian UGIS, WHO, and African green index to see the level of scarcity in park service area. As illustrated in
Fig. 7, the park deficit of the city was very high based on suggested standards by the Ethiopian UGIS, WHO, and average African per capita. Thus, the Addis Ababa city municipality has to increase the amount of urban park area by $6718.1,3962.9$, and 3044.5 ha to reach the minimum standards stated by Ethiopian UGIS, WHO and average per capita green index of Africa. This reveals that Addis Ababa city has a considerable deficit in UPs service and the city needs more additional recreational parks to satisfy the current demand.

Further, by using the same standards and analytical technique, park service area gap at the sub-city level was analyzed (Fig. 8). Based on the national UGIS of Ethiopia Kolfe Keraniyo (1071.2 ha) needs more park area followed by Yeka (862.3 ha), and Nefas Silk-Lafto (768.7 ha). Whereas, Akaki Kality (449.7 ha) and Arada (501.3 ha) sub-cities relatively need the smallest UPs acreage amongst other sub-cities.

\section{Discussion}

\section{The status and trend of urban green infrastructure}

UGI provides enormous environmental, economic, and social benefits that contribute to the quality of life in the cities (Kaczynski and Henderson 2008; Tabassum and Sharmin 2013; Wolch et al. 2014; Jennings et al. 2016). Sufficient amount of UGI is very essential for a sustainable urban environment and better quality of life. Our study also investigated the status of UGI in rapidly urbanizing city Addis Ababa to identify the challenges and show some policy direction for the city authority. Our result on the citywide analysis of the stutes of UGI for 
Table 2 Land use land cover of urban green infrastructure in 2003 and 2016

\begin{tabular}{|c|c|c|c|c|c|}
\hline \multirow{2}{*}{$\begin{array}{l}\text { Urban green infrastructure } \\
\text { and built-up area }\end{array}$} & \multicolumn{2}{|l|}{2003} & \multicolumn{2}{|l|}{2016} & \multirow{2}{*}{$\begin{array}{l}\text { Percentage } \\
\text { of change }\end{array}$} \\
\hline & Area/ha & LUP (\%) & Area/ha & LUP (\%) & \\
\hline \multicolumn{6}{|l|}{ Green infrastructure } \\
\hline Urban forest & 12,168 & 23.4 & $10,301.5$ & 19.7 & -3.7 \\
\hline River and river buffer green & 1144 & 2.2 & 4026.5 & 7.7 & +5.5 \\
\hline Urban agriculture & 7176 & 13.8 & 996.1 & 1.9 & -11.9 \\
\hline Urban parks & 468 & 0.9 & 938.7 & 1.8 & +0.9 \\
\hline Total & 20,956 & 40.3 & $16,262.8$ & 31.1 & -9.2 \\
\hline Built Up Area & 31,044 & 59.7 & $36,029.2$ & 68.9 & +9.2 \\
\hline Total Area & 52,000 & 100 & 52,292 & 100 & \\
\hline
\end{tabular}

the last two structural plan periods (2003-2016) shows a complex picture. Our finding clearly depicted that there had been a rapid decrease in the land use of UGI and at the same time increase in built up area in the city. The land use of urban agriculture decreased more significantly followed by urban forest. Similar findings were reported by previous studies conducted in the city. For instance, Abebe and Megento (2016) found the shrinking of urban green spaces, particularly urban forest and the increasing of built-up land use during the past three decades (1986-2015). Our study also revealed a dramatic decline of urban agriculture and forest land uses in the city during the last thirteen years. This finding is similar to the study conducted by Teferi and Abraha (2017) that pointed out built-up areas expanded dramatically in Addis Ababa, whereas UGI components such as forest and urban agriculture declined. Our findings also consistent with studies conducted in USA, Los Angeles-Long Beach-Santa Ana, where the percentage of urban green spaces decreased from $20.29 \%$ in 2005 to $18.20 \%$ in 2015 (Huang et al 2017). However, in contrary to our findings the studies conducted in 202 European cities identified an overall increase of $0.54 \%$ of urban green spaces annually between 2000 and 2006 (Kabisch and Haase 2013). This pattern may reflect the fact that the cities of developed countries are increasingly paying attention to develop and preserve UGI. This was partly in agreement with observations made by Richards et al. (2017) who found that developed countries city had more urban green spaces than developing countries.

\section{Spatial accessibility of existing urban parks}

UGI provides multiple benefits for urban environment (Jennings et al. 2016; Wolch et al. 2014). Provision of social service is one particular benefits of UGI especially recreational UPs. UPs provide places for physical activity; improves social cohesion and interaction; contribute to the social well-being and the health of the community (Kaczynski and Henderson 2008; Tabassum and Sharmin 2013). In order to enjoy these opportunities, city residents or users must have reasonable access to these resources. A starting point for inquiries about utilization of UGI is an assessment of their geographical or spatial accessibility (Khan and Shafqat 2014). Our study also investigated the status of existing UPs in the city from the sptial accessibility point of view by using park per capita and proximity indcators.

Our result in terms of park per capita indicated, the city has no sufficient amount of accessible recreational parks that serve the city residents. As per the existing land use analysis of the city, currently areas under existing UPs is around 168.7 ha for a population of more than 4.5 million, making the per capita availability of parks about $0.37 \mathrm{~m}^{2}$ (Table 4). This is insufficient and very small as per the standard set by Ethiopian UGIS $\left(15 \mathrm{~m}^{2}\right)$, WHO $\left(9 \mathrm{~m}^{2}\right)$ and the African green index $\left(7 \mathrm{~m}^{2}\right)$. It is far behind that of some African countries such as TunisTunisia $\left(14 \mathrm{~m}^{2}\right)$, Nairobi-Kenya $\left(37.3 \mathrm{~m}^{2}\right)$, Kumasi-Ghana $\left(4.7 \mathrm{~m}^{2}\right)$ and Egypt-Cairo $\left(0.8 \mathrm{~m}^{2}\right)$ (Langer and McNamara 2011). Addis Ababa city still lacks green image, compared to the per capita of other emerging cities of Ethiopia, 

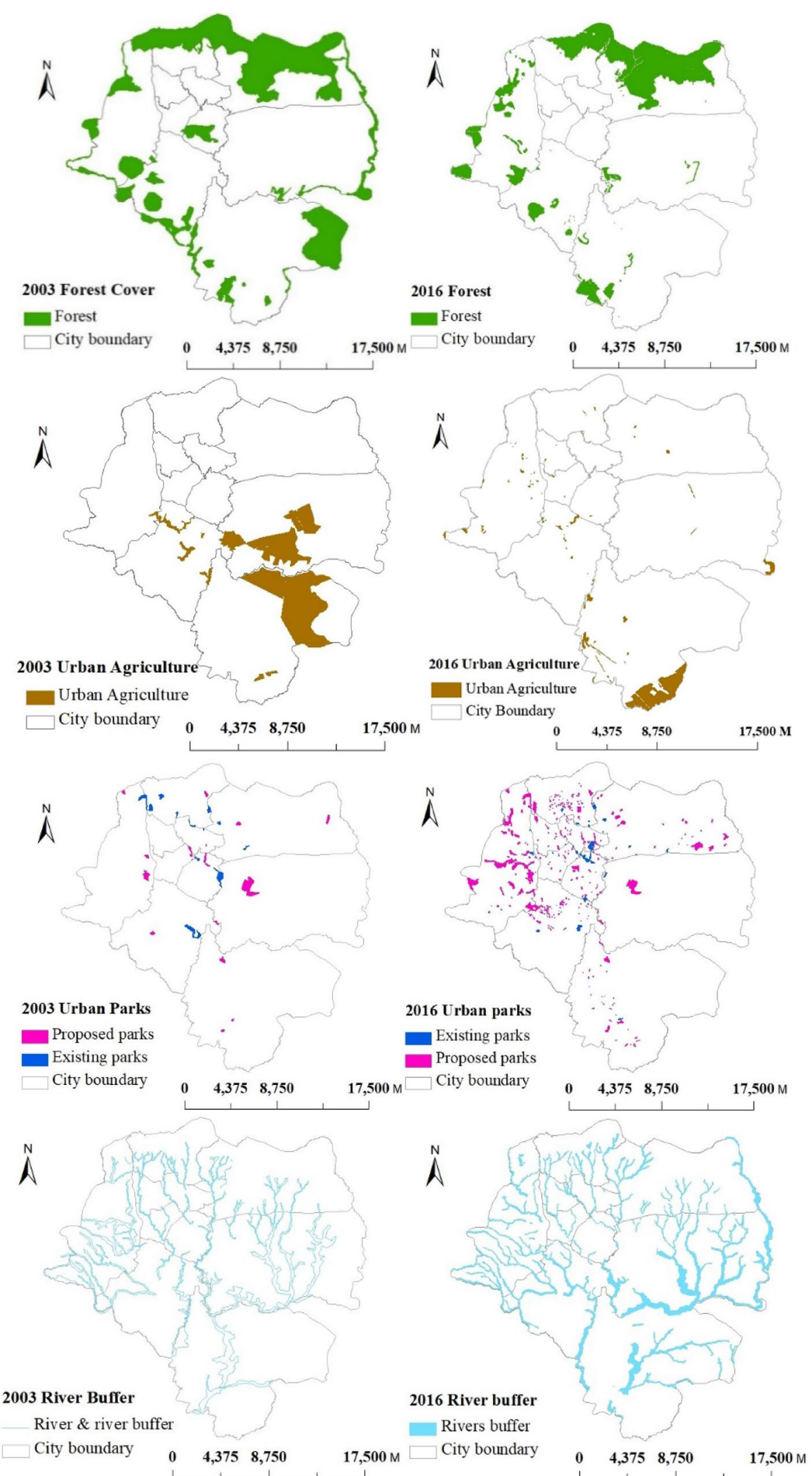

Fig. 4 Distribution of components of UGl land use for the year 2003 and 2016 in Addis Ababa 
Table 3 Proposed and existing urban parks in 2003 and 2016

\begin{tabular}{|c|c|c|c|c|c|}
\hline Sub-city & Existing UPs in 2003 & $\begin{array}{l}\text { Proposed UPs } \\
\text { in } 2003\end{array}$ & $\begin{array}{l}\text { Implemented UPs } \\
\text { in } 2012\end{array}$ & $\begin{array}{l}\text { Proposed UPs } \\
\text { in } 2016\end{array}$ & Existing UPs in 2020 \\
\hline Akaki Kality & - & $3(22.9)$ & $1(5.5)$ & $35(45)$ & $2(5.9)$ \\
\hline Nefas Silk Lafto & $1(46.4)$ & $1(8.4)$ & - & $163(79)$ & $3(26.4)$ \\
\hline Kolfe Keraniyo & $1(31.1)$ & $3(50.7)$ & $1(0.7)$ & $66(361)$ & $2(7.4)$ \\
\hline Gulelle & $4(45.1)$ & $1(10.6)$ & - & $105(65)$ & $4(18.2)$ \\
\hline Lideta & - & $2(10.8)$ & - & $17(19)$ & $6(6.5)$ \\
\hline Kirkos & $1(6)$ & $2(14.5)$ & - & $31(68)$ & $4(27.8)$ \\
\hline Arada & $2(5.3)$ & $1(0.8)$ & - & $31(24)$ & $3(30.6)$ \\
\hline Addis Ketema & - & - & - & $15(24)$ & - \\
\hline Yeka & $2(10.2)$ & $2(26.9)$ & - & $30(98)$ & $4(9.4)$ \\
\hline Bole & $1(44.7)$ & 1 (133.6) & - & $4(43)$ & $1(36.4)$ \\
\hline City Total & $12(188.8)$ & $16(279.2)$ & $2(6.2)$ & $504(825)$ & $29(168.7)$ \\
\hline
\end{tabular}

12 (188.8)-12 indicate the number of UPs, and 188.8 indicate the amount of UPs in hectare

Table 4 Currently existing urban parks coverage and per-capita in each sub city of Addis Ababa

\begin{tabular}{|c|c|c|c|c|c|c|}
\hline Sub-city & Area of sub city $\left(\mathrm{m}^{2}\right)$ & Total population & $\begin{array}{l}\text { Population } \\
\text { density } / \mathrm{km}^{2}\end{array}$ & Area of UPs $\left(\mathrm{m}^{2}\right)$ & UPs LU (\%) & $\begin{array}{l}\text { UPs Per- } \\
\text { capita } \\
\left(\mathrm{m}^{2}\right)\end{array}$ \\
\hline Akaki Kality & $123,455,172$ & 303,842 & 2461 & 58,845 & 0.05 & 0.2 \\
\hline Nefas Silk Lafto & $62,078,558$ & 530,150 & 8540 & 264,438 & 0.4 & 0.5 \\
\hline Kolfe Keraniyo & $63,492,540$ & 718,908 & 11,323 & 74,297 & 0.12 & 0.10 \\
\hline Gulelle & $31,193,194$ & 448,588 & 14,381 & 182,297 & 0.6 & 0.41 \\
\hline Lideta & $9,177,843$ & 338,109 & 36,840 & 65,252 & 0.7 & 0.19 \\
\hline Kirkos & $14,645,876$ & 370,830 & 25,320 & 278,315 & 1.9 & 0.75 \\
\hline Arada & $9,499,376$ & 354,515 & 37,320 & 306,405 & 3.2 & 0.86 \\
\hline Addis Ketema & $8,638,853$ & 428,051 & 49,550 & - & - & - \\
\hline Yeka & $86,130,129$ & 581,074 & 6746 & 93,942 & 0.1 & 0.16 \\
\hline Bole & $118,472,112$ & 517,933 & 4372 & 364,000 & 0.3 & 0.7 \\
\hline Total & $526,783,653$ & $4,592,000$ & 8717 & $1,687,791$ & 0.32 & 0.37 \\
\hline
\end{tabular}

LU- land use
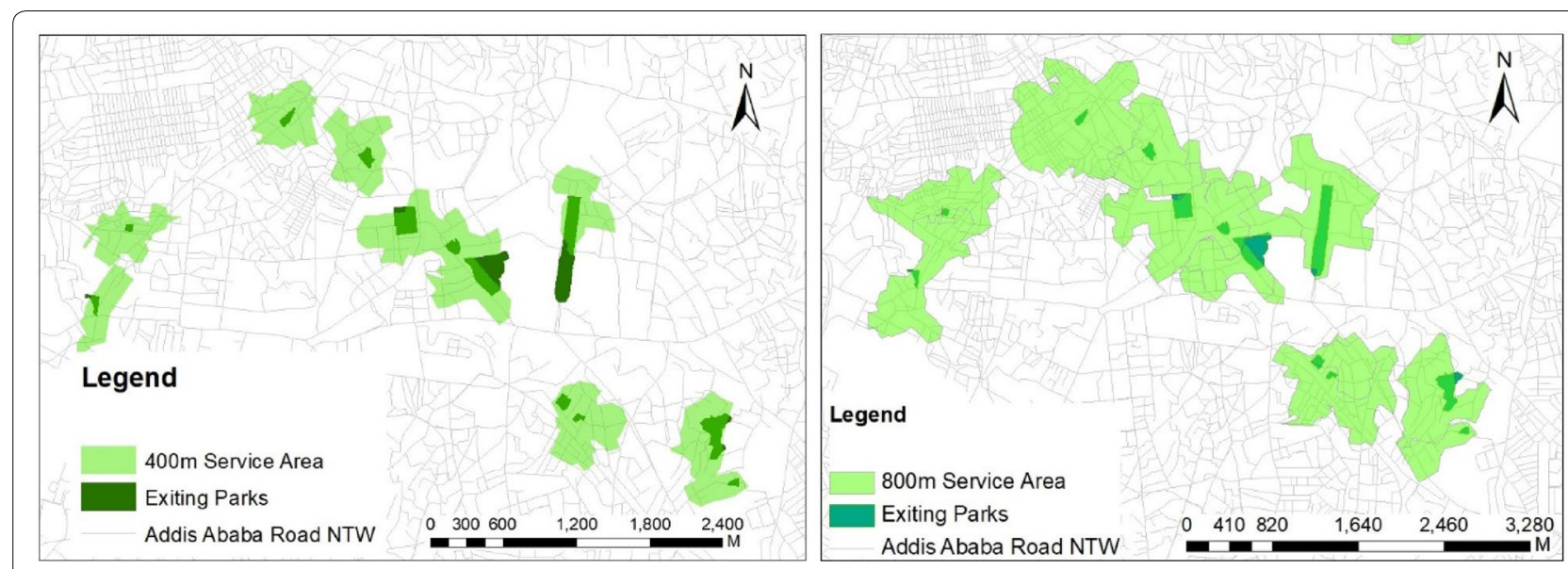

Fig. 5 Service area of urban parks by network analysis 


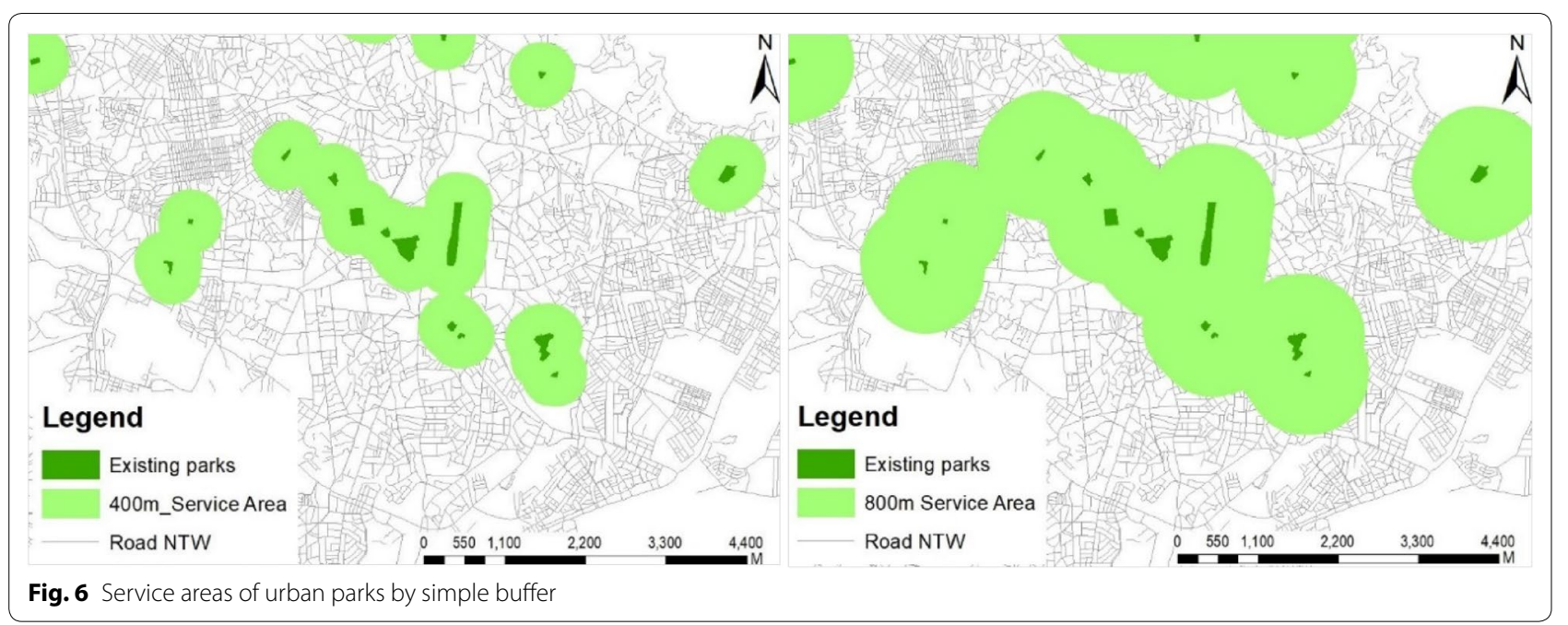

Table 5 The proximity of urban parks in Addis Ababa

\begin{tabular}{|c|c|c|c|c|c|c|}
\hline \multirow[t]{2}{*}{ Sub-city } & \multicolumn{3}{|l|}{$400 \mathrm{~m}$ distance } & \multicolumn{3}{|l|}{$800 \mathrm{~m}$ distance } \\
\hline & Service area $\left(\mathrm{m}^{2}\right)$ & Served pop & SA per pop. $\left(m^{2}\right)$ & Service area $\left(m^{2}\right)$ & Served pop & SA per pop. $\left(\mathrm{m}^{2}\right)$ \\
\hline Akaki Kality & $204,569(0.2)$ & $1098(0.4)$ & 186.3 & $886,737(0.8)$ & $4643(1.5)$ & 190.9 \\
\hline Nefas Silk-Lafto & $181,614(0.3)$ & $2023(0.4)$ & 89.8 & $1,353,737(1.9)$ & $13,627(2.6)$ & 99.3 \\
\hline Kolfe Keraniyo & $222,503(0.4)$ & $6819(0.9)$ & 32.6 & $891,915(1.5)$ & $25,126(3.5)$ & 35.5 \\
\hline Gulelle & $242,988(0.8)$ & $6007(1.3)$ & 40.4 & $1,387,861$ (4.6) & $36,291(8.1)$ & 38.2 \\
\hline Lideta & $851,670(9.3)$ & $68,965(20.4)$ & 12.3 & $3,110,300(33.8)$ & $224,717(66.5)$ & 13.8 \\
\hline Kirkos & $685,111(4.7)$ & $17,064(4.6)$ & 40.1 & $3,025,964(20.6)$ & 71,538 (19.3) & 42.3 \\
\hline Arada & $291,999(3.0)$ & $10,781(3.0)$ & 27.1 & $1,605,533(16.2)$ & $56,536(15.9)$ & 28.4 \\
\hline Addis Ketema & $54,293(0.7)$ & $1802(0.4)$ & 30.1 & 725,624 (9.8) & $22,734(5.3)$ & 31.9 \\
\hline Yeka & $456,339(0.5)$ & $10,820(1.9)$ & 42.2 & $2,691,543(3.1)$ & $60,234(10.4)$ & 44.7 \\
\hline Bole & $39,986(0.03)$ & $1004(0.2)$ & 39.8 & $220,054(0.2)$ & $5513(1.1)$ & 39.9 \\
\hline Total & $3,234,458(0.6)$ & $126,383(2.8)$ & 25.6 & $15,881,803(3.0)$ & $520,957(11.3)$ & 30.5 \\
\hline
\end{tabular}

(0.2) indicates percentage, Pop- refers to population, SA-Service area

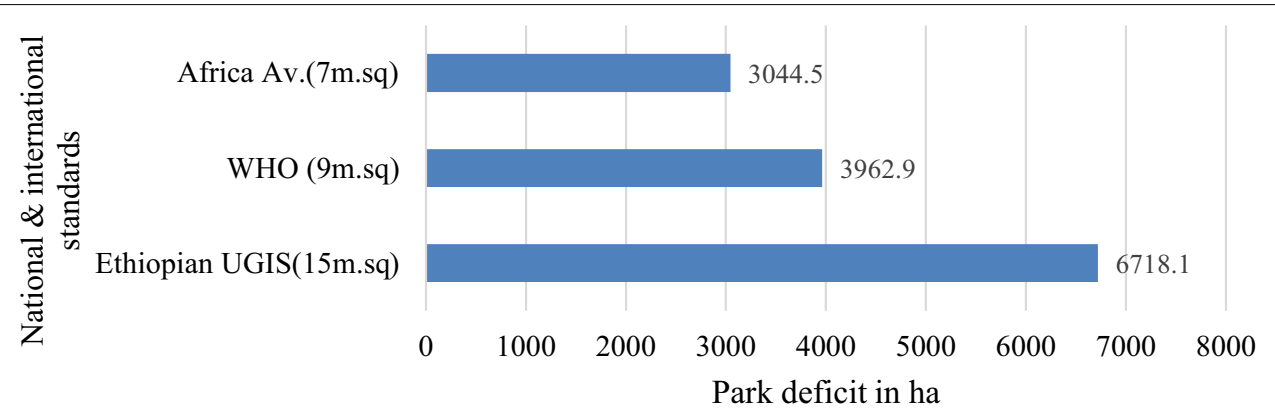

Fig. 7 Service area gap at municipal level 


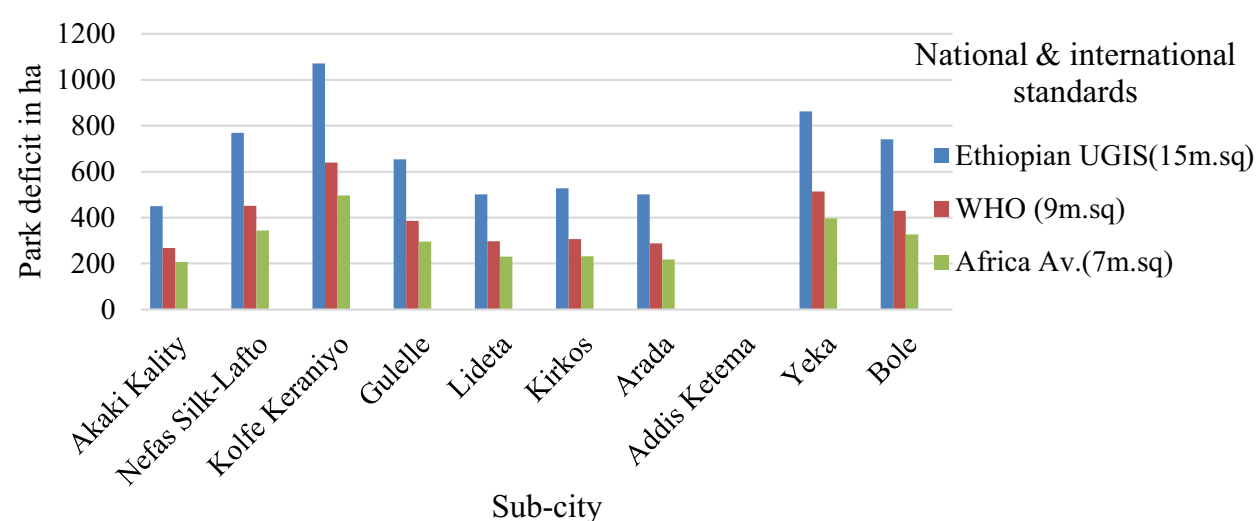

Fig. 8 Service area gap in sub-cities level

such as Adama $\left(2.1 \mathrm{~m}^{2}\right)$, Shashemene $\left(1.9 \mathrm{~m}^{2}\right)$, Dire Dawa $\left(5.6 \mathrm{~m}^{2}\right)$ and Bahir Dar $\left(8.2 \mathrm{~m}^{2}\right)$ cities (MoUD 2015).

In addition to the aforementioned park per capita indicator, our proximity analysis also revealed that the available UPs are not easily accessible for the city residents. The majority of the city residents are disadvantaged and forced to walk more than $400 \mathrm{~m}(97.2 \%)$ and $800 \mathrm{~m}(88.7 \%)$ distance to use UPs. Different studies that mapped the distance people travel to their nearest green space have also identified similar findings (Barbosa et al. 2007; Oh and Jeong 2007; Khalil 2014). For instance, the study conducted by Khalil (2014) found out that more than $70 \%$ of the population in Jeddah walk a distance of more than $500 \mathrm{~m}$ to use UPs. Van Herzele and Wiedemann (2003) also indicated, individuals do not have the same access within the walking distance and its distribution is not even. Moreover, our proximity analysis also revealed that the population in the outlying big sub-cities of Addis Ababa, such as Akaki Kality, Nifas Silek and Bole are the most disadvantaged in access to UPs. This is due to the fact that these sub-cities have very few parks that serve the community, and their population density is also lower than other sub-cities. Even though, the central sub-cities such as Lideta, Kirkos and Arada have better access to UPs, park congestion was more observed in these parts of the city. This is because these sub-cities are the most densely populated part of the city (Table 4 and Fig. 2a).

\section{Challenges and constraints behind the current status of urban green infrastructure}

As indicated above, there had been a rapid conversion and destruction of UGI land use in Addis Ababa city from 2003 to 2016. The available UGI such as recreational parks are also insufficient and not accessible to the majority of city residents. There are a number of factors that contributed to the degradation and inaccessibility of UGI in the city. Some of the major driving factors responsible for the current state of UGI may include; built up area expansion and density, insufficient operation of urban planning regulations, and lack of priority and attention given for UGI development. These challenges and constraints of UGI are analyzed based on the data collected through different techniques. They are initially derived from the result of the study and then, supported by the analyses of secondary materials, personal observations, and interviews with a variety of government organizations that are responsible for UGI management.

Development controls or master plans are tools or mechanisms used in urban planning to guide the growth of cities and improve the quality of life of the residents (Makworo and Mireri 2011). However, having development plans, policy or regulation is not enough by itself; unless there is an implementation or enforcement of these development controls. Our study investigated that lack of proper planning and implementation of UGI proposals were the main challenges of UGI access in the city. For instance, many of the proposed UPs (273 ha) in 2003 structural plan of the city were almost not implemented (Fig. 9). Through cross examination of the structural plan of the study area and the actual physical development that have taken place shows that areas demarcated on the structural plan as UPs were either non-existent or were converted into different land-uses. Similar studies conducted in Ghana, Kisumu also indicated that public parks and green spaces were found only in the city plan document, but not implemented on the ground (Collins 2014). Thomas (2013), who conducted a study in Addis Ababa indicated that lack of political will to implement the proposed parks as the main reason for the undersupply of UPs in the city. Expert interview also indicated, almost none of the master plans prepared at different 


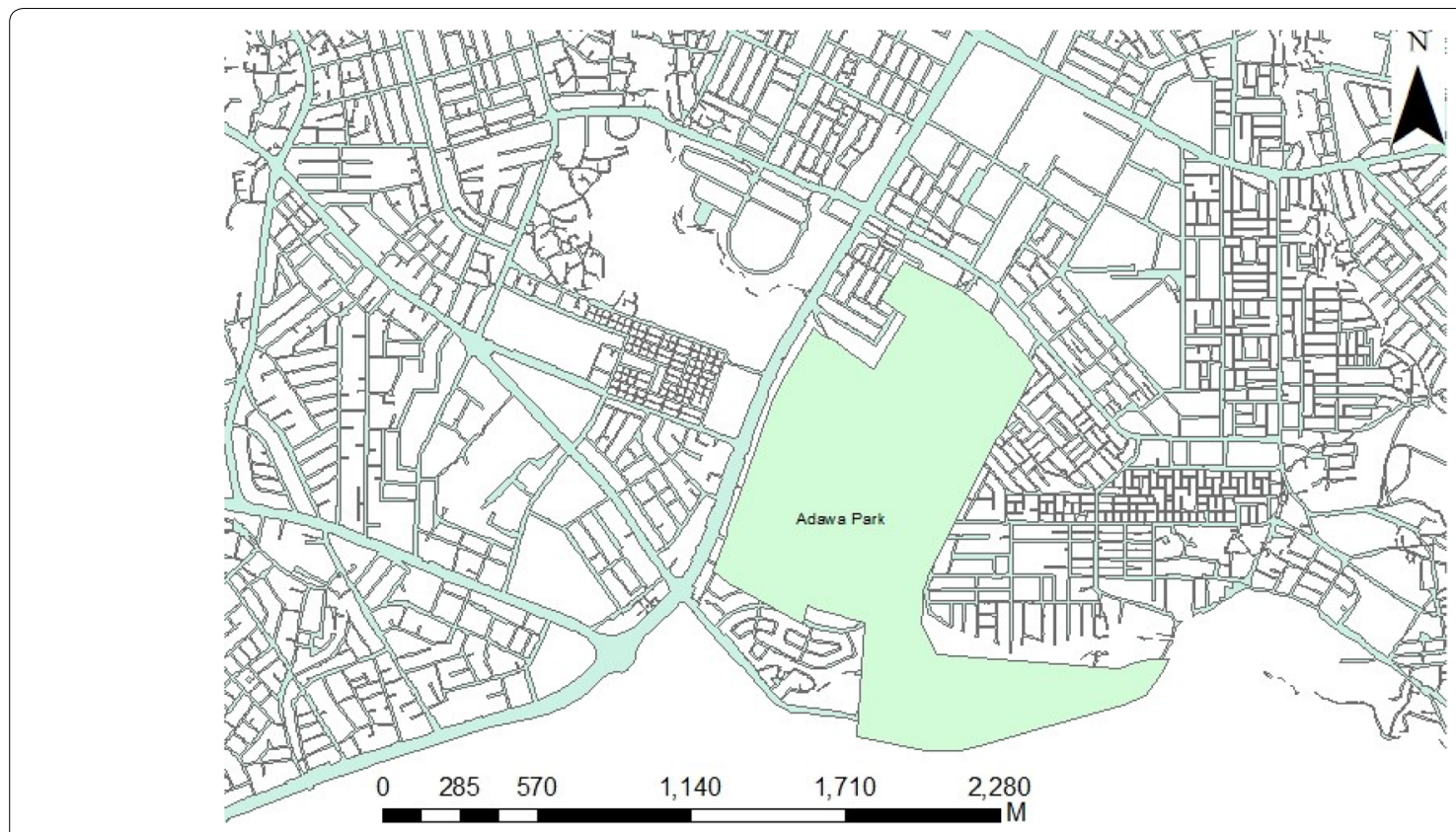

Fig. 9 Adawa Park - proposed park in 2003 and not developed yet

times have been effective, nor have they ever been fully implemented. The consequence of the weak enforcement of plans and regulations leads to the encroachment of most proposed river buffer strips by squatter and informal settlers. The same is true for other UGI components like UPs, forests and urban agricultural lands. In support of this finding, studies indicated that a lack of political desire to enforce regulations (Lara-Valencia and GarcíaPérez 2015); poor administration of planning processes at the local level; and a reluctance to make good planning decisions (Pincetl and Gearin 2005) can all affect the provision and implementation of UGI. Officials of the AABPCDA conceded that enforcement of development controls by their outfits has been very weak due to challenges like political interferences, lack of manpower and financial constraints.

Expansion of built up area is another cause for the depletion of UGI in the city. Our analyses indicated that there has been an increase in the percentage of built up land use from 2003 to 2016. This can be attributed to the rapid urbanization that takes place in Addis Ababa city over the past years. The city population was $1,423,111$ in 1984 , increased to $2,738,248$ in 2007 , and increased to $4,592,000$ in 2019 (CSA 2019), and this confirming the high growth rate of urbanization. This high growth rate of urbanization necessitates the provision of housing and different physical infrastructure to meet the needs of the increasing population in the city. Accordingly, the city administration has been constructing a 'social housing project' or 'condominium houses' by clearing green spaces and urban agricultural lands in the peripheral part of the city since 2004. The study conducted in the city indicated similar findings that more urban green spaces have been destroyed due to the physical expansion of built-up areas (Dubbale et al. 2010). The findings of Mundia and Aniya (2005) in Nairobi, Kenya also indicated in per-urban area, forests were cleared for urban settlements. Our result also supports the findings of many studies conducted in developed countries. For instance, the studies conducted in 274 metropolitan areas in the USA found the expansion of settlements to be the major factor that affected the availability of many green spaces (McDonald et al. 2010).

Moreover, in addition to the formal settlement expansion, informal settlement through land squatting has been contributing to the depletion of green spaces in Addis Ababa city. For instance, as illustrated in Fig. 10, the land reserved for UPs and forest area of the city was encroached by many informal settlements or urban sprawl. As mentioned above the cause of built up area expansion in Addis Ababa city is rapid urbanization. We conclude that rapid urbanization is the indirect driving factor for the depletion of UGI in the city. This rapid urbanization was partly attributed to the natural population growth and more of due to high migration from other parts of the country. As aforementioned, Addis Ababa is the capital of Ethiopia and this makes the city a nodal point to attract many settlers from all parts of the country and other countries as well. In support of this Tibbetts (2002) stated, developing countries have 


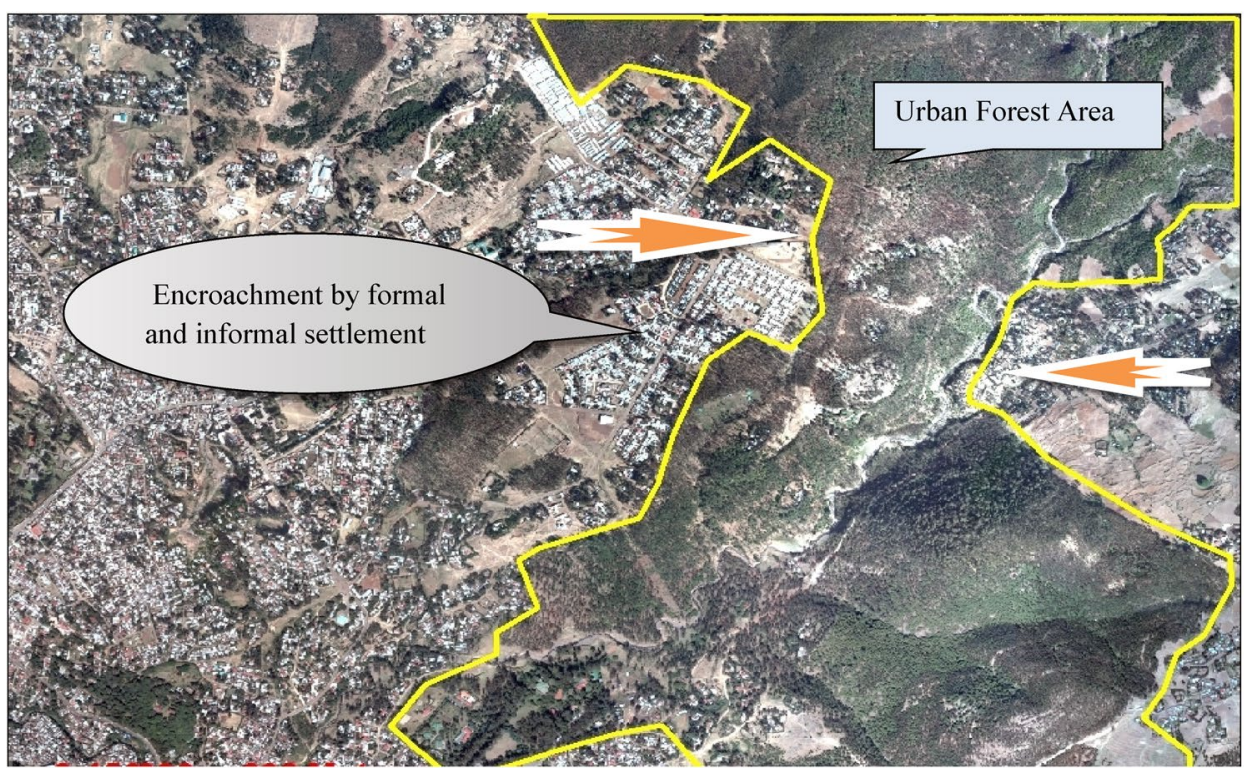

Fig. 10 The encroachment of upper catchment forest by urban expansion. Source: Aerial photograph of Addis Ababa

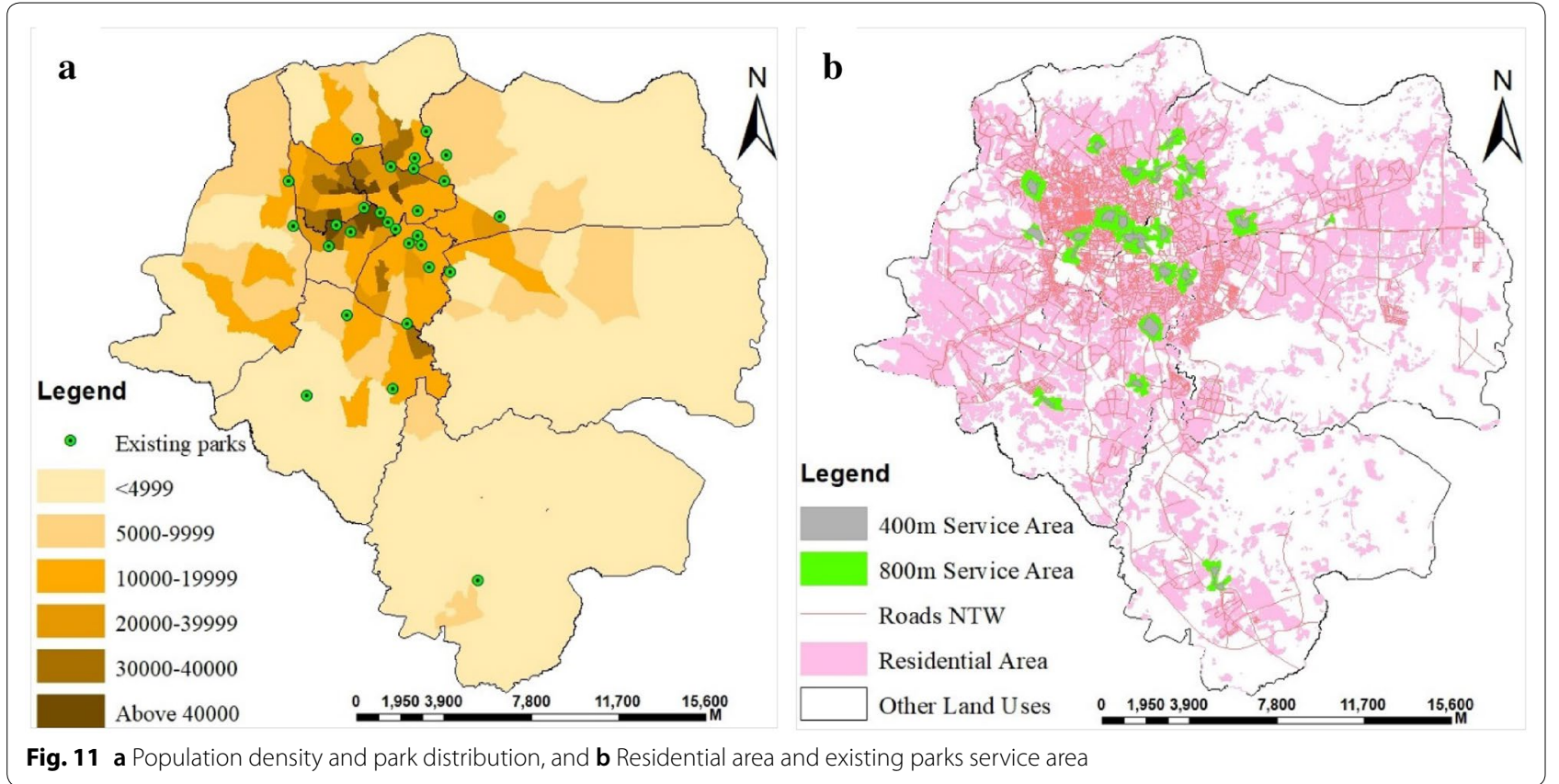

experienced high levels of movement of people from the countryside to cities and settlements of all sizes, but the most dramatic increase in populations is occurring in 'giant' cities, particularly in Africa and Asia. Thus, the city administrations should do more work to manage this rapid urbanization.

Population density is also another driving factor for the depletion and inaccessibility of UGI in the study area
(Fig. 11a). Our study revealed that the densest part of the city, especially the inner sub-cities of Addis Ababa, such as Lideta and Addis Ketama have a small amount of UGI and access to recreational parks. There is also high population pressure on the existing UPs of these sub-cities. This indicated population density is another driving factor that affected the availability of different components of UGI in Addis Ababa city (Fig. 3). Similar studies also 
frequently cited population density as a driver of decreasing in urban green spaces (Yuan et al. 2005; Tan and Samsudin 2017). Other studies also reported urban growth with a high density of residential development (Fig. 11b) has been recognized as a major factor that shaping the biosphere in the built up environment (Yuan et al. 2005; Teferi and Abraha 2017). However, such findings are not universal because some studies indicated that the dense inner city experienced higher green space. For instance, the study conducted in developed countries indicated increased housing density and streets have a positive influence on urban green spaces due to the presence of green lawns and trees in housing areas and along the streets (Dobbs et al. 2013).

Lack of priority and attention that is given to UGI indicated as the other factor for the degradation and insufficient provision of accessible UGI such as UPs (Collins 2014; Girma et al. 2019). The study conducted in Nairobi city also mentioned that green spaces for recreation and environmental protection are given low priority in the development and spatial planning of the city (Makworo and Mireri 2011). Similarly, in urban centers of Ethiopia especially in Addis Ababa, authorities did not give much attention and commit the needed funds for the development of components of UGI (Abeje 2007; Thomas 2013). The main reason for lack of priority for UGI especially UPs development in the city may be related to matters of poverty reduction. Addis Ababa city has gone through largely organic changes that have lacked a clearly defined urban patter and form. The city also characterized by lack of housing, poor social services and physical infrastructure such as road. Thus, the priority of the city authority is more on fulfilling these basic social services and gray infrastructure of the city than UGI development. Studies also indicated that matters of poverty reduction and provision of social amenities such as housing, roads, schools, hospitals, and pipe water service constitute the top priorities of many African countries (Bolnick et al. 2006). The same study also indicated, in Africa much attention is given to brown agenda by neglecting the green agenda (Bolnick et al. 2006). However, this is in contrary to the study conducted in developed countries (Sweden, Norway, Denmark) that found much attention given to green space development by the city authorities (Randrup and Persson's 2009). This is because developed countries already satisfied their need of gray infrastructure. The other reason for lack of priority for UPs development in the city may be related to the ignorance of the importance of UPs by the city authority. Our interview with experts indicated that UGI is not considered as an important resource by the city authorities. This is manifested by change in zoning of various categories of UGI that have already been proposed on the structural plan of the city. Most sub-cities of Addis Ababa have changed some of the proposed park area or other UGI to various land uses like residential and mixed land uses by requesting a zoning change from the municipality. Moreover, during revision of structural plan, plots unsuitable for building or other land use because of their shape or access have been left for UPs. This also indicated how much the city authority ignores the importance of UPs or other UGI components for the city.

\section{The policy implication of the study}

The findings and discussion indicated in previous sections suggest several policies and strategies, which might be used to improve the availability and increase the accessibilities of UGI in Addis Ababa city. First, our study investigated that components of UGI in the city are destroyed at an alarming rate due to encroachment by built up area such as formal/informal housing development and infrastructure expansion. Thus, one of the strategies to control encroachment onto UGI is strict adherence to or implementation of development plans and regulations. This strategy was highly recommended by the officials and experts of UGI planning and management of the city. Application of the concept of green infrastructure networking in the land use planning of the city is recommended as another strategy to reduce the destruction of green components and maintain sustainable urban environment. Development of green space networks is increasingly considered as a suitable approach to improve the ecological value of urban green space and the urban environment (Conine et al. 2004; Hepcan et al., 2009). Besides, interconnecting components of UGI in the entire landscape of the city would enable to generate substantial ecosystem service such as shade, regulation of air temperature and air pollution, and improve aesthetic values for the urban communities. The interconnectedness will be ensured through creating spatial integration of road and riverside greens with other components of UGI such as urban forest, agricultural areas, UPs and other green areas.

The per capita UPs of Addis Ababa city found to be $0.37 \mathrm{~m}^{2}$, which is far below the minimum standard set by Ethiopia UGIS and WHO. Moreover, the majority of the city population has no access to existing parks within the minimum walking distance that individuals are willing to walk. These problems were found to be underpinned by unavailability and uneven distribution of UPs due to inadequate provision of these recreational facilities during the past decades. The city needs more additional recreational park acreage (6718.1 ha) to fulfill the current need of the city residents (Fig. 7). Thus, the particular strategy that could be implemented to improve park access in the city is providing small to medium size UPs 
at different scales of the city. Studies also indicated that the accessibility of green space can be expanded in the city by building more small-to-medium sized green space (Tabassum and Sharmin 2013). In Addis Ababa, such UPs can be developed on lands that have already been proposed for UPs developments. For instance, the 2016 structural plan of the city allocated 825 ha of land for UPs development, but yet they remain undeveloped on the ground (Table 3). A typical example of such reserved space is Adawa Park (112.3 ha) in Bole sub-city which was proposed in 2003 and not developed yet (Fig. 9). In addition, developing UPs in condominium housing and real estate development sites as well as peripheral expansion area of the city is also another option to enhance access to recreational parks in the city.

Moreover, the densest and the oldest sub cities (Lideta, Kirkos, and Arada) of Addis Ababa have also fewer amounts of UGI and accessible recreational parks. In these sub-cities the provision of large parks might be difficult because of the scarcity of land. Thus, in such parts of the city pocket/small parks are one option for enhancing park access. Although pocket parks might be too small for physical activities, they can meet a variety of social needs and functions, including small event space, children's playground, and spaces for relaxation. Spaces like vacant building lots, small and irregular pieces of land, unused areas, abandoned spaces, and rooftops are appropriate for converting into small parks. Providing small to medium size parks in renewal parts of these subcities can also be another solution to minimize the high demand of recreational parks.

Providing universal access to green spaces and urban parks is a target of the sustainable development goals (SDGs) adopted by the international society in 2015 (Conghong et al. 2017). However, our study can indicated that the environmental sustainability issue is not recognized and considered by the city authority. Due to this the urban environment of the city is deteriorating and problems like air pollution and urban heat island are becoming the major challenges of the city. Thus, this calls for legislation, policies and strategies backed by scientific studies that consider the SDGs mentioned above.

\section{Conclusion}

UGI in general and UPs in particular are important settings for improving the quality of urban life. Overall, this study provided important findings that show the status, accessibility and different determinant factors that affect UGI, which has seldom been assessed before in Addis Ababa city, Ethiopia. Our study yielded four important findings. First, this study investigated that components of UGI in the city are destroying at an alarming rate and their distribution is also unequal within the city. Second, the accessibility indicators also revealed that the city residents have no sufficient UGI access such as recreational parks. The city's park per capita was very small $\left(0.37 \mathrm{~m}^{2}\right)$ compared with Ethiopian UGIS $\left(15 \mathrm{~m}^{2}\right)$ and the large portion of the city population (above 90\%) has no access to UPs within the minimum walking distance thresholds. Thus, the city needs more additional park acreage (6718.1 ha) to fulfill the current demand. Third, our study investigated that the encroachment of UGI by built up area, population density, weak enforcement of policies, plans and regulations, as well as lack of priority for UGI development are the major constraints behind the current state of UGI in the city. In the city urban park provision is, thus confirmed as a crucial issue to be addressed in order to enhance the worsening built environment of the city. Besides this, as one strategy, the strict adherence to the development plans and regulations is very important to maintain UGI in the city. Planning for green space networks could further improve the quantity and quality of the UGI of Addis Ababa city considerably. Developing small to median size parks in already proposed areas, new expansion and renewal parts of the city is another alternative to enhance recreational park access.

Moreover, this study has several strengths. As far as we are aware, this is the first empirical study that addressed the status, accessibility and challenges of UGI in Addis Ababa, Ethiopia. Thus, it provides a good starting point for future research and more in-depth evaluation of UGI in the city as well as other urban centers of the country. Moreover, this study can serve as the benchmark for decision makers and it has the potential to assist in identifying priority areas so as to ensure adequate and accessible UGI in Addis Ababa.

With regards to future studies, there are several issues that need further research in the study area. First, this study is concerned only about the spatial aspect of UGI and population that have and have not access UGI such as UPs. The study did not take into account the characteristics and quality of UPs that may determine the accessibility of UPs in the city. Thus, future researches should analyze information about the facilities, quality, and other physical environment of UPs as well as park user's condition that may affect park access. Secondly, in this study, the accessibility of UPs is generalized in terms of objective measurement, and the needs, preference, and perception of different population segments was not considered. Thus, subjective based urban park accessibility analysis should be addressed in the future research.

\section{Abbreviations}

AAEPA: Addis Ababa Environmental Protection Agency; AABPCDAA:

Addis Ababa City Beautification, Parks and Cemetery Development and 
Administration Agency; AAIDPO: Addis Ababa City Integrated Development Plan Project Office; CSA: Central Statistics Agency; UGIS: Urban Green Infrastructure Standard; GIS: Geographic Information System; NDVI: Normalized Difference Vegetation Index; SDGs: Sustainable Development Goals; UGI: Urban Green Infrastructure; UPs: Urban Parks; WHO: World Health Organization.

\section{Acknowledgements}

The authors would like to thank Addis Ababa University Thematic Area Research Fund for supporting the cost of data collection and fieldwork of this study. In addition, we would like to thank the officials of Addis Ababa City Beautification, Parks and Cemetery Development and Administration Agency (AABPCDAA) and the Addis Ababa City Integrated Development Plan Project Office (AAIDPO) for providing us information on the urban green infrastructure.

\section{Authors' contributions}

This manuscript was entirely elaborated and written by both authors. Both authors read and approved the final manuscript.

\section{Funding}

Not applicable.

\section{Availability of data and materials}

All data generated or analyzed during this study are included in this published article.

\section{Ethics approval and consent to participate}

Not applicable.

\section{Consent for publication}

Not applicable.

\section{Competing interests}

The authors declare that they have no competing interests.

\section{Author details}

1 Department of Civil Engineering, Haramaya Institute of Technology (HiT), Haramaya University, P.O. Box-138, Dire Dawa, Ethiopia. ${ }^{2}$ Ethiopian Institute of Architecture, Building Construction \& City Development (EiABC), Addis Ababa University, P. O. Box-518, Addis Ababa, Ethiopia.

Received: 15 July 2020 Accepted: 19 September 2020

Published online: 06 October 2020

\section{References}

Abebe MT, Megento TL (2016) The city of Addis Ababa from 'Forest city' to 'Urban Heat Island'. Assessment of urban green space dynamics. J Urban Environ Eng. 10(2):254-262

Abeje W (2007) Which urban livelihood without adequate breathing space? A reflection on the green areas of Addis Ababa, Ethiopia. In: Proceedings of the First Green Forum Conference held in Addis Ababa, Ethiopia, 2-4 October 2006. https://www.phe-ethiopia.org/pdf/Ethiopian_Environmen t Review.pdf. Accessed 2 Apr 2019

Adjei MC (2014) Destruction of urban green spaces: a problem beyond urbanization in Kumasi City. Ghana Am J Environ Prot 3(1):1-9

Anguluri R, Narayanan P (2017) Role of green space in urban planning: outlook towards smart cities. Urban For Urban Green 25:58-65

Attwell K (2000) Urban land resources and urban planning: case studies from Denmark. Landsc Urban Plan 52(2):145-163

Barbosa O, Tratalos JA, Armsworth PR, Davies RG, Fuller RA et al (2007) Who benefits from access to green space? A case study from Sheffield, UK. Landsc Urban Plan 83:187-195

Baycan-Levent T, Nijkamp P (2009) Planning and management of urban green spaces in Europe: comparative analysis. J Urban Plan Dev 135(1):1-12

Bolnick J, Kayuni HM, Mabala R, McGranahan G, Mitlin D, Nkhoma S et al (2006) A pro-poor urban agenda for Africa: Clarifying ecological and development issues for poor and vulnerable population. International Institute for Environment and Development, London
Boone CG, Buckley GL, Grove JM, Sister C (2009) Parks and people: an environmental justice inquiry in Baltimore, Maryland. Ann Assoc Am Geogr 99:767-787

Coles R, Grayson N (2004) Improving the quality of life in Urban regions though Urban Greening Initiatives-EU URGE-Project. https://www.resea rchgate.net/publication/237553539_Improving_the_Quality_of_Life_in_ Urban_Regions_Through_Urban_Greening_Initiatives_-_EU_URGE-Proje ct. Accessed 10 Mar 2020

Collins AM (2014) Destruction of urban green spaces: a problem beyond urbanization in Kumasi City (Ghana). Am J Environ Prot 3(1):1-9

Conghong $H$, Jun Y, Hui L, Huabing H, Le Y (2017) Green spaces as an indicator of urban health: evaluating its changes in 28 mega-cities. Remote Sens 9(12): 1266

Conine A, Xiang WN, Young J, Whitley D (2004) Planning for multipurpose greenways in Concord, North Carolina. Landsc Urban Plan 68:271-287

CSA (2017) Population and housing census annual report of Ethiopia, Central Statistic Authority of Ethiopia, Addis Ababa

CSA (2019) Population and housing census annual report of Ethiopia, Central Statistic Authority of Ethiopia, Addis Ababa

De la Barrera F, Rayes-Paecke S, Banzhaf E (2016) Indicators for green spaces in contrasting urban settings. Ecol Indic 62:212-219

Dubbale DA, Tsutsumi J, Bendewald MJ (2010) Urban environmental challenges in developing cities: the case of Ethiopian capital Addis Ababa. World Acad Sci Eng Technol 4(6):397-402

EEA (2002) Toward an urban atlas: assessment of spatial data on 25 European cities and urban areas. Environmental Issue Rep. 30, European Environment Agency, Copenhagen

Fetene A, Worku H (2013) Planning for the conservation and sustainable use of urban forestry in Addis Ababa, Ethiopia. Urban For Urban Green 12(3):367-379

Foster J, Lowe A, Winkelman S (2011) The value of green infrastructure for urban climate adaptation: the Center for Clean Air Policy. https://ccap. org/assets/The-Value-of-Green-Infrastructure-for-Urban-Climate-Adapt ation_CCAP-Feb-2011.pdf. Accessed 7 Jun 2020.

Giles-Corti B, Broomhall MH, Knuiman M, Collins C, Douglas K, Ng K, Lange A, Donovan RJ (2005) Increasing walking. How important is distance to, attractiveness, and size of public open space? Am J Prev Med 28(2):169-176

Girma Y, Terefe H, Pauleit S (2019) Urban green spaces use and management in rapidly urbanizing countries: the case of emerging towns of Oromia Special Zone Surrounding Finfinne, Ethiopia. Urban For Urban Green. https://doi.org/10.1016/j.ufug.2019.05.019

Gret-Regamey A, Brunner SH, Altwegg J, Christen M, Bebi P (2013) Integrating expert knowledge into mapping ecosystem service trade-offs for sustainable forest management. Ecol Soc. https://doi.org/10.5751/ES-05800 $-180334$

Hepcan S, Hepcana CC, Bouwmab IM, Jongman RHG, Özkana MB (2009) Ecological networks as a new approach for nature conservation in Turkey: a case study of Izmir Province. Landsc Urban Plan 90:143-154

Huang C, Yang J, Lu H, Huang H, Yu L (2017) Green spaces as an indicator of urban health: evaluating its changes in 28 mega-cities. Remote Sens 9:1266. https://doi.org/10.3390/rs9121266

Jennings V, Larson L, Yun J (2016) Advancing sustainability through urban green space: cultural ecosystem services, equity, and social determinants of health. Int J Environ Res Pub He 13(2):196

Jensen F, Koch N (2004) Twenty-five years of forest recreation research in Denmark and its influence on forest policy. Scand J Forest Res 19(4):93-102

Kabisch N, Haase D (2013) Green spaces of European cities revisited for 1990-2006. Landsc Urban Plan 110(1):113-122

Kaczynski AT, Henderson KA (2008) Parks and recreation settings and active living: a review of associations with physical activity function and intensity. J Phys Activ Health 5(4):619-632

Khalil R (2014) Quantitative evaluation of distribution and accessibility of urban green spaces (Case study: City of Jeddah). International Journal of geometrics and geosciences 4(3).

Khan AA, Shafqat A (2014) Assessing the spatial distribution and allocation gaps of urban parks in Bahawalpur City of Punjab, Pakistan. Pak J Soc Sci 34(2):545-561

La Rosa D (2014) Accessibility to green spaces: GIS based indicators for sustainable planning in a dense urban context. Ecol Indic 42(7):122-134 
Lahotia S, Lahotib A, Saitoa O (2019) Benchmark assessment of recreational public Urban Green space provisions: a case of typical urbanizing Indian City, Nagpur. Urban For Urban Green 44:126424

Langer H, McNamara J (2011) Africa green city index. Munich: Siemens AG. https://www.siemens.com/entry/cc/features/greencityindex.../all/.../repor t_africa_en.pdf.Accessed 26 Apr 2020.

Lara-Valencia F, García-Pérez H (2015) Space for equity: Socioeconomic variations in the provision of public parks in Hermosillo. Mexico Local Environ 20(3):350

Liu Y, Huang X, Yang H, Zhong T (2014) Environmental effects of land-use/ cover change caused by urbanization and policies in Southwest China Karst area-a case study of Guiyang. Habitat Int 44:339-348

Makworo M, Mireri C (2011) Public open spaces in Nairobi City, Kenya, under threat. J Environ Plan Manag 54(8):1107-1123. https://doi. org/10.1080/09640568.2010.549631

McDonald RI, Forman RT, Kareiva P (2010) Open space loss and land inequality in United States' cities, 1990-2000. PLoS ONE 5(3):e9509. https://doi. org/10.1371/journal.pone.0009509

MoUD (2015) Ethiopian national urban green infrastructure standards. Ministry of Urban Development and Housing, Addis Ababa, Ethiopia

Mohamed MS, Zhirayr V (2013) The benefits of urban parks: a review of urban research. J Novel Appl Sci 2:231-237

Mundia CN, Aniya M (2005) Analysis of land use/cover changes and urban expansion of Nairobi city using remote sensing and GIS. Int J Remote Sens 26:2831-2849

Nicholls S (2001) Measuring the accessibility and equity of public parks: a case study using GIS. Managing Leisure 6(4):201-219

Nielsen T, Hansen KB (2007) Do green areas affect health? Results from Danish survey on the use of green areas and health indicators. Health \& Place 13(4):839-850

Oh K, Jeong S (2007) Assessing the spatial distribution of urban parks using GIS. Landsc Urban Plan 82:25-32

Pincetl S, Gearin E (2005) The reinvention of public green space. Urban Geog 26(5):365-384

Randrup TB, Persson B (2009) Public green space in the Nordic countries: development of a new strategic management regime. Urban For Urban Green 8:31-40

Richards DR, Passy P, Oh RR (2017) Impacts of population density and wealth on the quantity and structure of urban green space in tropical Southeast Asia. Landsc Urban Plan 157:553-560

Sister C, Wilson J, Wolch J (2007) The green visions plan for 21st century Southern California Park congestion and strategies to increase park equity. University of Southern California, GIS Research Laboratory and Center for Sustainable Cities, Los Angeles

Tabassum S, Sharmin F (2013) Accessibility analysis of parks at urban neighborhood: the case of Dhaka. Asian J Appl Sci Eng 2(2):148-160
Tan PY, Samsudin R (2017) Effects of spatial scale on assessment of spatial equity of urban park provision. Landsc Urban Plan 158:139-154

Taylor BT, Fernando P, Bauman AE, Williamson A, Craig JC, Redman S (2011) Measuring the quality of public open space using Google earth. Am J Prev Med 40(2):105-112

Teferi E, Abraha H (2017) Urban heat Island effect of Addis Ababa City: implications of urban green spaces for climate change adaptation. In: Filho WL, Belay S, Kalangu J, Menas W, Munishi P, Musiyiwa K (eds) Climate change adaptation in Africa. Springer, Cham, pp 539-552

Thomas PZ (2013) Environmental challenges of urbanization: a case study of open green space management in Addis Ababa, Ethiopia. Res J Agri Environ Manag 2(4):105-110

Thompson M (1996) A standard land-cover classification for remote-sensing applications in South Africa. S Afr J Sci 92:34-42

Tibbetts J (2002) Coastal cities living on the edge. Environmental Health Perspect. 110(11):674-681

United Nations, Department of Economic and Social Affairs (2014) World urbanization prospects. The 2014 revision highlights.https://esa.un.org/ unpd/wup/publications/files/wup2014-highlights.pdf. Accessed 30 Mar 2020.

Van Herzele A, Wiedemann T (2003) A monitoring tool for the provision of accessible and attractive urban green spaces. Landsc Urban Plan 63:109-126

Wang XJ (2009) Analysis of problems in urban green space system planning in China. J For Res 20(1):79-82

WHO (2016) Urban green spaces and health: a review of evidence. World Health Organization, Geneva, Switzerland. https://www.euro.who.int/ data/assets/pdf_file/0005/321971/Urban-green-spacesand-health-revie w-evidence.pdf?ua=1. Accessed 1 Jun 2020.

Wolch JR, Byrne J, Newell JP (2014) Urban green space public health and environmental justice: the challenge of making cities 'just green enough'. Landsc Urban Plan 125:234-244

Wright HE, Downs JA, Mihelcic JR (2011) Assessing equitable access to urban green space: the role of engineered water infrastructure. Environ Sci Technol 45(16):6728-6734

Yao L, Liu J, Wang R, Yin K, Han B (2014) Effective green equivalent-a measure of public green spaces for cities. Ecol Indic 47:123-127

Yuan F, Sawaya KE, Loeffelholz BC, Bauer ME (2005) Land cover classification and change analysis of the Twin Cities (Minnesota) metropolitan area by multi temporal landsat remote sensing. Remote Sens Environ 98(2-3):317-328

\section{Publisher's Note}

Springer Nature remains neutral with regard to jurisdictional claims in published maps and institutional affiliations.

\section{Submit your manuscript to a SpringerOpen ${ }^{\odot}$ journal and benefit from:}

- Convenient online submission

- Rigorous peer review

- Open access: articles freely available online

- High visibility within the field

Retaining the copyright to your article

Submit your next manuscript at springeropen.com 